JOSÉ ERASMO DAL'COL LÚCIO

\title{
Alterações antropométricas na base do crânio em crianças com craniostenose sagital
} submetidas à correção cirúrgica

Tese apresentada à Faculdade de Medicina da Universidade de São Paulo para obtenção do título de Doutor em Ciências

Programa de: Neurologia

Orientador: Prof. Dr. Hamilton Matushita

São Paulo 
Dados Internacionais de Catalogação na Publicação (CIP)

Preparada pela Biblioteca da

Faculdade de Medicina da Universidade de São Paulo

Creprodução autorizada pelo autor

Lúcio, José Erasmo Dal’Col

Alterações antropométricas na base do crânio em crianças com craniostenose sagital submetidos à correção cirúrgica / José Erasmo Dal’Col Lúcio. -- São Paulo, 2011.

Tese(doutorado)--Faculdade de Medicina da Universidade de São Paulo. Programa de Neurologia.

Orientador: Hamilton Matushita.

Descritores: 1.Craniossinostose 2.Craniostenose sagital 3.Escafocefalia 4.Base do crânio 5.Antropometria

USP/FM/DBD-019/11 


\section{DEDICATÓRIA}


A meu filho Lucas

e minha esposa Shoraya 
A meus pais Genibaldo e Teresa e minha irmã Ana Cecília, pelo apoio irrestrito em todos os momentos de minha vida e por sempre acreditarem em $\operatorname{mim}$.

A meu irmão Alessandro, pelo apoio na análise estatística de meus dados e pelas orientações constantes.

Ao Prof. Dr. Hamilton Matushita, pela orientação precisa e tranquila, pelo exemplo de neurocirurgião pediátrico e por compartilhar comigo seus conhecimentos e sua técnica, minha gratidão.

Ao Prof. Dr. José Píndaro Pereira Plese, orientador inicial deste trabalho, por participar de minha formação neurocirúrgica e pelas orientações ponderadas.

Aos amigos da DFVneuro: Vellutini, Felix, Taricco, Mutarelli, Marcos, Capel, Tarso, Vitor e Felippe, por confiarem em meu trabalho, pela oportunidade que me dão em fazer uma neurocirurgia de ponta e por incentivarem meu crescimento pessoal e profissional.

À amiga e incentivadora Maria Inês Braconi, pela participação ativa em minha formação técnica e sobretudo pela amizade.

Aos amigos de todas as horas: Roger, Patrícia, Rodrigo, Suyanne, Daniel, Flávia, Paula, Felipe, Fernanda, Jovana, Rafaela e Douglas, pela amizade, por dividirem momentos importantes de minha vida e por estarem sempre presentes. Nosso companheirismo é soberano a qualquer diferença nesta caminhada.

Aos médicos residentes do HC-FMUSP, pelo auxílio nas cirurgias e nos cuidados pré e pós-operatórios dos pacientes.

Aos pais que aceitaram incluir seus filhos neste estudo, confiando-me o ser mais importante de suas vidas e sentindo-se seguros com meu trabalho. 
Esta tese está de acordo com as normas em vigor no momento da publicação:

Referência: adaptado de International Commitee of Medical Journals Editors (Vancouver)

Universidade de São Paulo. Faculdade de Medicina. Serviço de Biblioteca e Documentação. Guia de apresentação de dissertações, teses e monografias. Elaborado por Anneliese Carneiro da Cunha, Maria Júlia de A. L. Freddi, Maria F. Crestana, Marinalva de Souza Aragão, Suely Campos Cardoso, Valéria Vilhena, $2^{\mathrm{a}} \mathrm{Ed}$. São Paulo: Serviço de Biblioteca e Documentação; 2005.

Abreviaturas dos títulos dos periódicos de acordo com List of Journals Indexed in Index Medicus. 
SUMÁRIO 
Lista de figuras

Lista de tabelas

Lista de Gráficos

Resumo

Summary

1 INTRODUÇÃO

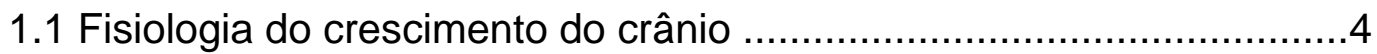

1.1.1 Desenvolvimento da base do crânio ..................................

1.1.2 Desenvolvimento da calota craniana .................................11

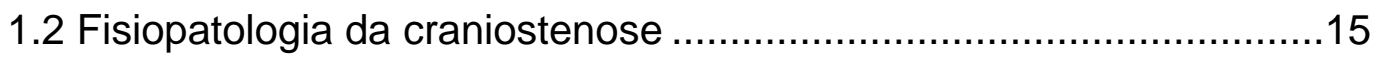

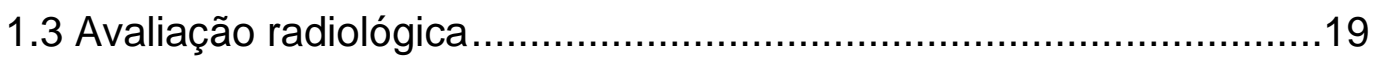

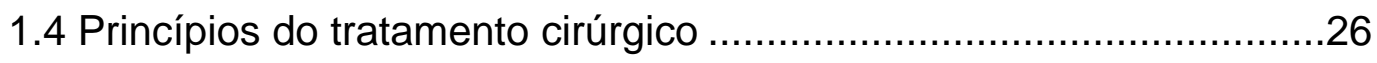

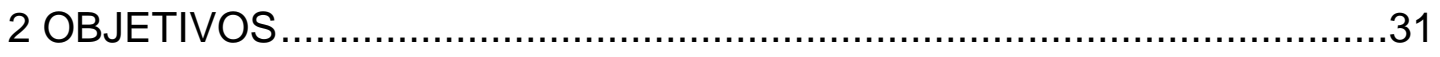

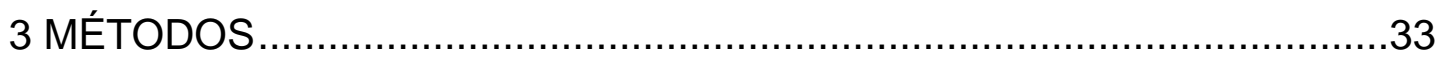

4 RESULTADOS

5 DISCUSSÃO

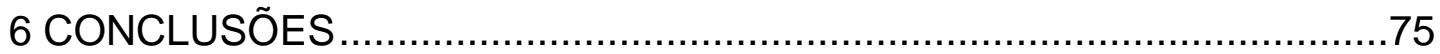

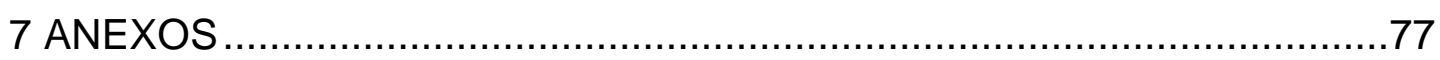

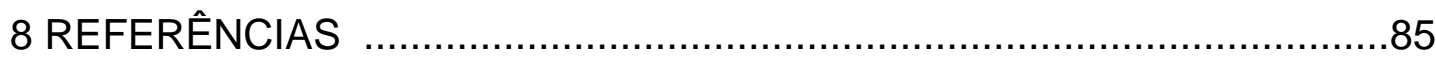


LISTAS 


\section{LISTA DE FIGURAS}

Figura 1 - Condrocrânio no Homo sapiens ....................................

Figura 2 - Visão superior da base do crânio e sagital do crânio ................8

Figura 3 - Centros de ossificação da calota craniana ..........................12

Figura 4 - Planos de secção na tomografia computadorizada................25

Figura 5 - Fotografia pré-operatória em perfil do paciente MNF .............35

Figura 6 - Fotografia pré-operatória com visão anterior do paciente

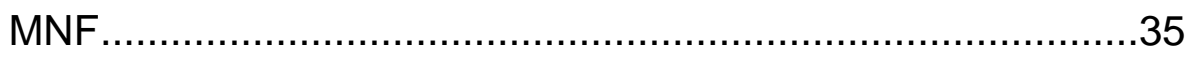

Figura 7 - Fotografia pré-operatória com visão superior do paciente MNF

Figura 8 - Tomografia computadorizada de crânio com reconstrução em três dimensões do paciente JVDN

Figura 9 - Fotografia intraoperatória do paciente LFCB, mostrando o posicionamento da cabeça para a cirurgia 39

Figura 10 - Fotografia intraoperatória do paciente LEA, mostrando a marcação da incisão do couro cabeludo em zigue-zague 39

Figura 11 - Fotografia intraoperatória do paciente LEA, mostrando a exposição da calota craniana

Figura 12 - Fotografia intraoperatória do paciente GCC

Figura 13 - Fotografia intraoperatória do paciente LEA .43

Figura 14 - Fotografia intraoperatória do paciente JVSS - Visão anterior 
Figura 15 - Fotografia intraoperatória do paciente JVSS - Visão lateral...

Figura 16 - Fotografia intraoperatória do paciente VGGC .45

Figura 17 - Fotografia intraoperatória do paciente VGGC - Visão superior, após a realização das osteotomias

Figura 18 - Fotografia intraoperatória do paciente VGGC Resultado cirúrgico final .46

Figura 19 - Comprimento do crânio .48

Figura 20 - Largura do crânio 49

Figura 21 - Distância entre o início da crista galli e o tubérculo selar 49

Figura 22 - Distância entre a crista galli e o meato acústico interno. .50

Figura 23 - Distância entre os meatos acústicos internos .50

Figura 24 - Distância entre os forames ovais. .51

Figura 25 - Ângulo da base do crânio .51

Figura 26 - Ângulo formado entre o násio, o centro selar e o opístio .52

Figura 27 - Fotografias com visão lateral pré e pós-operatórias .62

Figura 28 - Medidas antropométricas pré e pós-operatórias da base do crânio 


\section{LISTA DE TABELAS}

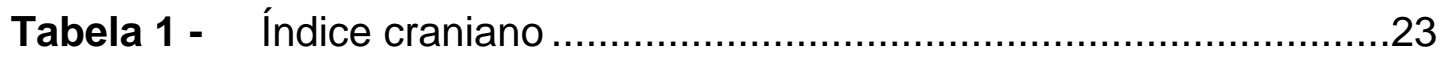

Tabela 2 - I Índice craniano calculado pela tomografia de crânio, com reconstrução em três dimensões ....................................23

Tabela 3 - Alterações nas medidas pré e pós-operatórias do comprimento, largura e índice craniano .56

Tabela 4 - $\quad$ Alterações nas medidas pré e pós operatórias da base do crânio. .59

Tabela 5 - $\quad$ Ângulos da base do crânio .60

Tabela 6 - Crescimento proporcional das medidas antropométricas do crânio 61

Tabela 7 - Identificação dos pacientes .78

Tabela 8 - Medidas antropométricas .82 


\section{LISTA DE GRÁFICOS}

Gráfico 1 - Índice craniano pré-operatório........................................57

Gráfico 2 - Índice craniano pós-operatório .....................................57

Gráfico 3 - Comparação do índice craniano pós-operatório com o

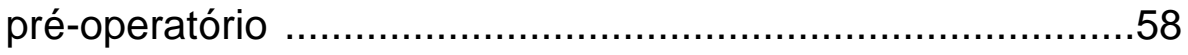


Lúcio JEDC. Alterações antropométricas na base do crânio em crianças com craniostenose sagital submetidas à correção cirúrgica [tese]. São Paulo: Faculdade de Medicina, Universidade de São Paulo, 2011. 96 p.

Craniostenose é o fechamento precoce de uma ou mais suturas cranianas, levando ao redirecionamento do crescimento craniofacial e à deformidade do crânio. Estudos têm pesquisado o impacto da fusão da sutura sagital na base do crânio, focalizando a morfologia da base do crânio na presença de craniostenose sagital isolada (escafocefalia), enquanto outros têm avaliado o crescimento da base do crânio, antes e após a cirurgia. Este estudo teve como objetivo realizar as medidas antropométricas da base do crânio em crianças com escafocefalia, avaliar a influência da correção cirúrgica no remodelamento da base do crânio e nas medidas antropométricas. Foram operadas 21 crianças com diagnóstico clínico e radiológico de escafocefalia, entre abril de 2007 e outubro de 2008, sendo realizadas medidas antropométricas na base do crânio, antes e após 1 ano do tratamento cirúrgico. As medidas foram o índice craniano (IC), distância entre a crista galli e o tubérculo selar (CG-TS), distância entre a crista galli e o meato acústico interno (CG-MAl), distância entre os forames ovais (FO-FO), distância entre os meatos Acústicos internos (MAI-MAI), o ângulo da base do crânio Â1) e o ângulo entre o násio, centro selar e básio (Â2). Houve normalização do IC em todas as crianças, confirmando um remodelamento craniano adequado. A medida CG-TS avaliou a base do crânio anterior, com crescimento proporcional de $12,5 \%$. O crescimento médio-lateral foi observado pelo aumento das medidas FO-FO de 8,5\% e MAI-MAI de 9,5\%. A medida CG-MAl teve um crescimento de 7,2\%. Não houve diferença estatística nos ângulos basais Â1 e Â2 analisados. O tratamento cirúrgico da escafocefalia levou ao remodelamento da base do crânio, confirmado pelas mudanças das medidas antropométricas realizadas antes e após 1 ano da cirurgia.

Descritores: craniossinostose, craniostenose sagital, escafocefalia, base do crânio, antropometria. 
Lucio JEDC. Anthropometric changes in the skull base in children with sagittal craniosynostosis submitted to surgical correction [thesis]. São Paulo: "Faculdade de Medicina, Universidade de São Paulo", 2011. 96 p.

Craniosynostosis is defined as the premature closure of one or more sutures, leading to redirection of the craniofacial growth and deformity of the skull. Studies have examined the impact of fusion of the sagittal suture in the skull base, focusing on the morphology of the skull base in the presence of isolated sagittal craniosynostosis (scaphocephaly), while others have evaluated the growth of the skull base before and after surgery. This study aims to perform the anthropometric measures of the skull base in children with scaphocephaly to evaluate the influence of surgical repair in the remodeling of the skull base and anthropometric measures. Twenty-one children with clinical and radiological diagnosis of scaphocephaly were operated between April 2007 and October 2008, and anthropometric measures at the base of the skull were performed before and after a year of surgery. The measures were the cranial index $(\mathrm{Cl})$, distance between the crista galli and tuberculum sellar (CG-TS), distance between the crista galli and the internal auditory meatus (CG-IAM), distance between the oval foramen (OF-OF) distance between the internal auditory meatus (IAM-IAM), the angle of the skull base (Â1) and the angle between the nasion, center of sella and basion (Â2). There was a normalization of the $\mathrm{Cl}$ in all children, confirming an appropriate cranial remodeling. The CG-TS measure evaluated the anterior skull base, with proportional growth of $12.5 \%$. The mediolateral growth was observed by the increase of OF-OF measures by $8.5 \%$ and IAM-IAM by $9.5 \%$. The CG-IAM measure grew by $7.2 \%$. There was no statistical difference in the angles Â1 and Â2 analyzed. Surgical treatment of scaphocephaly led to remodeling of the skull base, confirmed by the changes of anthropometric measures taken before and after a year of surgery.

Descriptors: sagittal craniosynostosis, scaphocephaly, skull base, anthropometry. 
Alterações na forma do crânio têm sido objeto de interesse por séculos. Em algumas civilizações antigas, os indivíduos tinham seus crânios intencionalmente deformados, como forma de identificar membros de uma mesma tribo ou reconhecer as diferentes hierarquias dentro do mesmo grupo (Persing, 2000).

Hipocrates, Galeno e Celsius há mais de 23 séculos, já mencionavam os formatos anormais dos crânios e os relacionavam com a ausência de suturas e com pessoas com cefaleia. Sömmerring ${ }^{*}$ (1800) apud Cohen Jr (1986) descreve a estrutura das suturas e sua importância no crescimento do crânio. Os primeiros avanços na compreensão da deformidade ocorrem com Otto $^{\dagger}$ (1830) apud Cohen Jr (1986) que descreve o fechamento prematuro da sutura resultando em uma deformidade craniana e utiliza pela primeira vez o termo craniostenose e com Virchow ${ }^{\ddagger}$ (1851) apud Cohen Jr (1986), apud Park e Robinson (2001), apud Sgouros (2005), que descreveu as características do crescimento anormal do crânio.

Estudos experimentais de deformidades cranianas em modelos animais demonstraram a relação entre o neurocrânio e a base do crânio (Moss, 1975).

\footnotetext{
* Sömmerring ST. Vom baue des menschlichen köpers. Voss; Leipzig; Germany; 1800.

${ }^{\dagger}$ Otto AW. Lehrbuch der pathologischen anatomie. Rücker; Berlin; 1830.

‡ Virchow R. Über dem cretinismus, manentlich in franken, und uber pathollogische schadelformen. Verh Physikalische-Medizinische Gesellschaft in Wurzburg. 1851;2:230-270.
} 
Muitos estudos têm pesquisado o impacto da fusão da sutura sagital sobre a base do crânio, focalizando sobretudo a morfologia da base do crânio na presença de craniostenose sagital isolada (Carmel et al., 1981; Slomic et al., 1992), enquanto outros têm avaliado o crescimento da base do crânio, antes e após a liberação da sutura (Richtsmeier et al., 1998). Estes estudos indicam que a fusão da sutura sagital causa uma redução do crescimento médio-lateral da base do crânio e uma hiper-rotação do crânio, como resultado de um movimento posterior e inferior sobre um ponto da base do crânio previamente estabelecido, a sela túrcica, tornando o ângulo formado pelo násio, sela túrcica e pelo básio mais agudo (Deleon et al., 2001).

A craniostenose sagital, também denominada escafocefalia, é a forma mais comum do fechamento isolado de uma sutura craniana, com uma incidência de, aproximadamente, 1 em 2.000 a 4.000 nascidos vivos e, correspondendo de $40 \%$ a $60 \%$ das craniostenoses primárias isoladas (RuizCorrea et al., 2006; Fearon et al., 2006; Schmelzer et al., 2007; Persing, 2008; Antúnez et al.,2009). Existe uma predileção pelo sexo masculino, com uma relação de 4:1 com o sexo feminino (Zeiger et al., 2002; Persing, 2008).

Crianças com escafocefalia apresentam um aumento do neurocrânio no eixo anteroposterior e uma restrição no crescimento laterolateral, quando comparadas às crianças sem deformidade craniana na mesma faixa etária (Slomic, 1992; Richtsmeier, 1998).

O grau de comprometimento do crânio na escafocefalia é quantificado por meio do Índice Craniano (IC), primeiramente, usado pelo anatomista 
Andréas Retzius, em 1842 (Ruiz-Correa et al., 2006). Entretanto, o grau de fusão da sutura, da deformidade do crânio e das alterações adicionais como a bossa frontal e occipital, e o estreitamento parietal podem variar significativamente entre os indivíduos (Ruiz-Correa et al., 2006).

Na tentativa de corrigir o neurocrânio para sua forma normal, como indicação estética e diminuir a possibilidade de aumento da pressão intracraniana ou comprometimento do desenvolvimento cognitivo, a maioria das crianças com escafocefalia é submetida à correção cirúrgica, tendo como principal tática cirúrgica a remoção da linha de sutura fechada, denominada suturectomia, seguida do remodelamento do crânio (David e Simpson, 1982; Park e Robinson, 2001).

Embora o tratamento cirúrgico tenha demonstrado a melhora da morfologia do neurocrânio nos casos de escafocefalia, os efeitos específicos da correção cirúrgica sobre a base do crânio ainda permanecem pouco esclarecidos.

\subsection{FISIOLOGIA DO CRESCIMENTO DO CRÂNIO}

\subsubsection{Desenvolvimento da base do crânio}

A base do crânio aparece primeiramente no $2^{\circ}$ mês da vida embrionária, como uma plataforma cartilaginosa de forma estreita e irregular, denominada condrocrânio, situada ventralmente ao cérebro 
embrionário. Em torno do $28^{\circ}$ dia de gestação, inicia-se o desenvolvimento do condrocrânio, como condensações das células da crista neural e do mesoderma paraxial na ectomeninge (Sperber, 1989).

$\mathrm{Na} 7^{\circ}$ semana de gestação, o condrocrânio diferencia-se em nove grupos de precursores cartilaginosos dos ossos da base do crânio. Os grupos anteriores à notocorda derivam da crista neural e são os aliesfenoidais, pré-esfenoidais, orbitoesfenoidais, mesoetmoidais e a cápsula nasal. Os grupos posteriores à notocorda derivam do mesoderma e são as quatro condensações occipitais, cartilagem para-cordal, cápsula ótica e cartilagem hipofisária (Lieberman et al., 2000) (Figura 1). Consequentemente, o meio do corpo do osso esfenoide marca a divisão entre as porções anterior e posterior da base do crânio que são embriologicamente distintas (Noden, 1991).
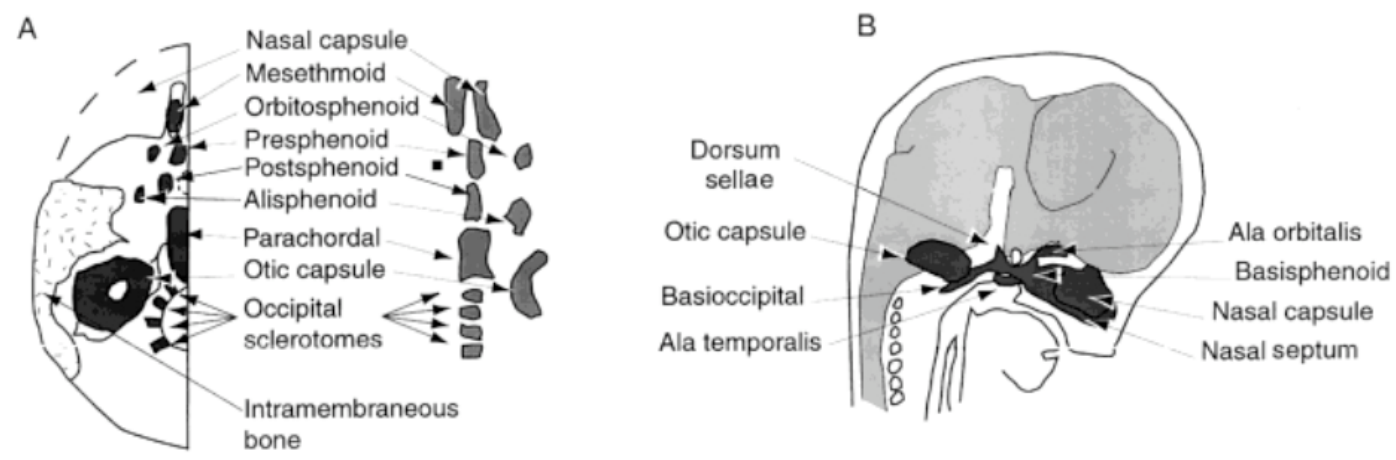

Figura 1 - Condrocrânio no Homo sapiens. A: visão superior dos precursores cartilaginosos e dos centros de ossificação. B: visão lateral dos precursores cartilaginosos em um feto de 8 semanas de gestação. (FONTE: Lieberman DE, Ross CF, Ravosa MJ. The primate cranial base: ontogeny, function, and integration. Yearbook of Anthropology. 2000; 43:117-69) 
$\mathrm{Na} 8^{\circ}$ semana de gestação, aparecem pelo menos 41 centros de ossificação no condrocrânio, que são responsáveis pela sua transformação no basicrânio. Estes centros formam uma plataforma perfurada e irregular conhecida como lâmina basal (Sperber, 1989; Kjaer, 1990) (Figura 1).

Em geral, a ossificação começa nas cartilagens derivadas do mesoderma na porção mais caudal do condrocrânio e prossegue rostral e lateralmente, formando os quatro principais ossos do basicrânio: etmoide, esfenoide, parte do osso occipital e parte do osso temporal (Williams et al, 1995; Lieberman et al, 2000).

A ossificação a partir das cartilagens derivadas do mesoderma é denominada de ossificação endocrondral e é responsável pelo alargamento da base do crânio (Enlow, 1986; Lieberman et al., 2000).

Para compreender como o basicrânio cresce durante o período fetal e pós-natal são importantes três princípios de seu desenvolvimento. Primeiro, a parte central do basicrânio atinge a forma e o tamanho adulto mais rápido que as partes anterior, posterior e lateral, presumivelmente porque quase todos os nervos cranianos e maiores vasos perfuram a base do crânio nesta região. Segundo, o crescimento da porção anterior e posterior ocorre independente, por terem origens embriológicas distintas, diferenças espaciais e funcionais. Terceiro, o crescimento das fossas cranianas anterior, média e posterior também ocorre independentemente (Sperber, 1989; Lieberman et al., 2000). 
Silverman (1976) mostra a importância das suturas frontoesfenoidais, frontoetmoidais e esfenozigomáticas no processo de crescimento e alargamento da base do crânio. O crescimento em largura das fossas cranianas anterior e média verifica-se pelas suturas frontoesfenoidais e o crescimento anteroposterior das três fossas cranianas pelas suturas frontoetmoidal e esfenozigomática.

Após a formação inicial, a base do crânio cresce por um série complexa de eventos, em grande parte por remodelamento nas margens ósseas e por deslocamento ósseo. As principais formas de crescimento que ocorrem na face endocranial da base do crânio são o crescimento anteroposterior e médio-lateral, por meio do remodelamento e deslocamento ósseo, e a angulação (Lieberman et al., 2000).

No crescimento anteroposterior, verifica-se um remodelamento ósseo às margens anterior e posterior da base; um deslocamento no plano coronal orientado pela sutura frontoesfenoidal e um deslocamento na linha média orientado pelas sincondroses médio-esfenoidal, esfenoetmoidal e esfenooccipital (Figura 2A). O crescimento anteroposterior da porção occipital da base do crânio é proporcionalmente menor no exoccipício e na escama occipital posterior, causando uma rotação do plano nucal na direção inferior, tornando o forame magno em uma posição mais horizontalizada (Figura 2B). Após o nascimento, o crescimento da base posterior ocorre por meio da deposição óssea na sincondrose esfeno-occipital, por remodelamento no forame magno e mais lateralmente, por deposição óssea na sutura occipitomastoideia e remodelamento posterior (Lieberman et al., 2000). 
Durante o período fetal, a linha média da base do crânio anterior cresce sobretudo por meio do crescimento etmoidal. No período pós-natal, o crescimento da base do crânio anterior ocorre na sincondrose esfenoetmoidal, no deslocamento na sutura frontoesfenoidal e pelo remodelamento na margem anterior do osso frontal. A sincondrose esfenoetmoidal permanece em atividade até 6 a 8 anos, após o nascimento, quando se completa o crescimento cerebral (Sven Kreiborg, 1986; Lieberman et al., 2000).

A
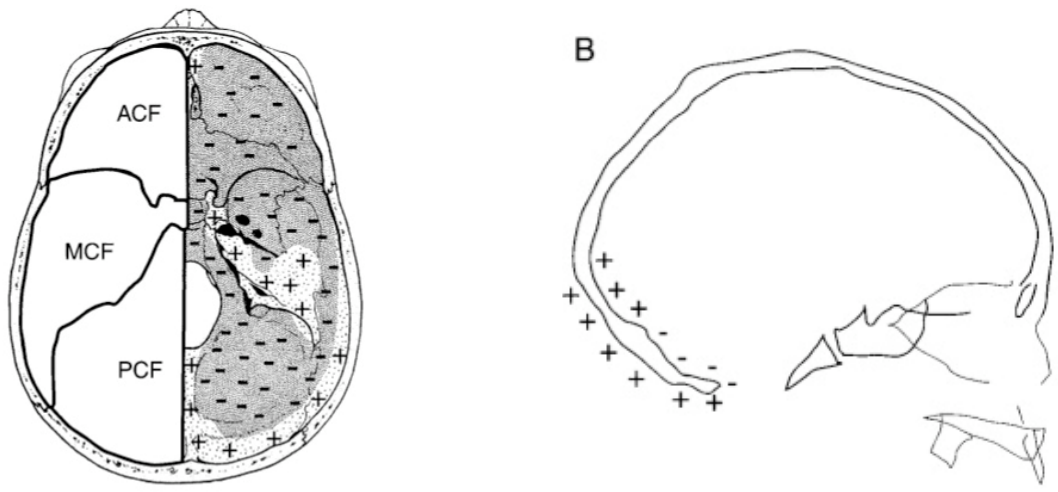

Figura 2 - Visão superior da base do crânio (A) e sagital do crânio (B). As áreas de deposição óssea são marcadas com o sinal + e as áreas de reabsorção óssea com o sinal - . ACF: fossa craniana anterior; MCF: fossa craniana média; PCF: fossa craniana posterior. (FONTE: Lieberman DE, Ross CF, Ravosa MJ. The primate cranial base: ontogeny, function, and integration. Yearbook of Anthropology. 2000; 43:117-69)

No crescimento médio-lateral da base do crânio, o aumento da largura das fossas anterior e posterior ocorre primariamente por deposição e reabsorção óssea e por crescimento ósseo intramembranoso nas suturas 
frontoetmoidal e occipitomastoideia. Muito do alargamento da fossa média verifica-se pela sutura esfenotemporal e pela deposição e reabsorção óssea lateral na porção escamosa do esfenoide (Sperber, 1989; Lieberman et al., 2000).

A angulação da base do crânio ocorre quando as porções pré-cordal e pós-cordal do basicrânio sofrem flexão ou extensão no plano mediossagital, formando um ângulo entre o násio, a sela túrcica e o básio (Hoyte, 1991; Lieberman et al., 2000).

Durante o $2^{\circ}$ e o início do terceiro trimestre de gestação, ocorre uma extensão no ângulo da base do crânio em cerca de $9^{\circ}$, seguida, após 0 nascimento, de uma flexão, que é maior no primeiro ano de vida (Jeffery e Spoor, 2002).

O aumento da atividade condrogênica na face superior das sincondroses, sobretudo na sincondrose esfeno-occipital, leva à flexão na base do crânio, enquanto o aumento da atividade na porção inferior das sincondroses leva à extensão na base do crânio (Jeffery e Spoor, 2002; Lieberman et al., 2000).

Enquanto a porção médio-ventral e áreas restritas mais laterais da base do crânio são originadas do condrocrânio fetal, a maior parte da base do crânio lateral tem origem intramembranosa. Uma vez estabelecida no período pré-natal, até os ossos cartilaginosos são compostos em grande parte por tecido ósseo intramembranoso compacto e esponjoso. Apenas as áreas próximas às sincondroses têm verdadeiramente um osso cartilaginoso e quando um novo tecido ósseo é formado, torna-se em grande parte 
substituído pelo tecido ósseo intramembranoso e pelo remodelamento esponjoso grosseiro. A sincondrose funciona como um centro regulador do crescimento da base do crânio (Enlow, 1986).

Como todos os elementos ósseos da base do crânio tornam-se separados de suas suturas por movimentos de deslocamento, causados pelo crescimento do cérebro, há um alargamento ósseo nas suturas associado ao processo de remodelamento (Enlow, 1986).

O alargamento da base do crânio é um processo de crescimento multifatorial. A fossa craniana média expande-se anteriormente pela reabsorção endocranial em sua superfície anterior e deposição óssea nas suturas, em conjunto com o deslocamento anterior da fossa craniana anterior. A porção petrosa entre as fossas cranianas média e posterior alarga-se por deposição endocranial e o clívus alonga-se pela sincondrose esfeno-occipital. Nas partes mais inferiores da base do crânio, observa-se que a superfície endocranial causa mais reabsorção óssea (Enlow, 1986; Lieberman et al., 2000; Jeffery e Spoor, 2002). 


\subsubsection{Desenvolvimento da calota craniana}

A morfogênese dos ossos da calota craniana e do complexo facial é um longo processo de desenvolvimento que se inicia no período embrionário e se completa durante a vida adulta (Opperman, 2000).

Ao final da gastrulação, as três camadas primárias de tecido do embrião estão formadas (ectoderma, mesoderma e endoderma). A quarta camada de tecido, o mesênquima, começa a ser identificada com a migração da placa neural e aproximação e fechamento das pregas neurais, que ocorrem entre 7 e 8 dias, antes do aparecimento da matrix óssea da calota (Lemire, 1986).

O crescimento rápido do cérebro inicia e define o desenvolvimento diferencial dos componentes da calota craniana, por meio da organização do mesênquina a seu redor em duas camadas: a mais profunda é a endomeninge, que formará a pia-máter e a aracnoide, e a mais superficial é a ectomeninge, que formará a dura-máter e os ossos da calota craniana (David et al., 1982).

Em estudo experimental, Nodem (1992) mostra que os ossos membranosos da calota craniana, o periósteo sobrejacente e as suturas são originados no mesoderma paraxial, enquanto a dura-máter origina-se na placa neural. Entretanto, apesar de não ter uma contribuição direta na formação dos ossos membranosos, as células da placa neural têm uma contribuição indireta pela indução da formação óssea quando a dura-máter neonatal está na presença de tecido epitelial (Yu, 1997; Opperman, 2000). 
Em torno da $6^{a}$ semana de gestação, ocorre a formação dos centros de ossificação craniana originados da ectomeninge, iniciando o desenvolvimento dos ossos frontais, parietais, segmento interparietal do osso occipital, segmento orbitotemporal da asa maior do esfenóide e da escama do osso temporal. A calota craniana não estará completa até o final do primeiro ano de vida (David et al., 1982) (Figura 3).

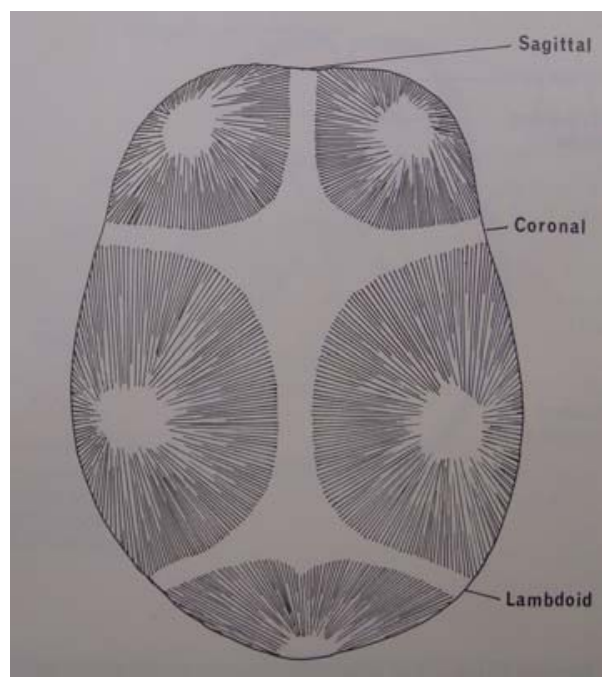

Figura 3 - Centros de ossificação da calota craniana. Observa-se a extensão centrífuga em direção às futuras linhas de suturas (FONTE: David DJ, Poswillo, Simpson DA. The craniosynostoses: cases, natural history and management. New York: Springer-Verlag; 1982)

Frente ao rápido crescimento e expansão do cérebro, os ossos da calota craniana mantêm uma flexibilidade como forma de protegê-lo. Essa flexibilidade é proporcionada pela presença das fontanelas e das suturas (David et al.; 1982). 
As suturas são um tipo de articulação em que as bordas ósseas estão unidas por uma fina camada de tecido fibroso e são encontradas apenas no complexo craniofacial. Durante o crescimento e desenvolvimento normal, as suturas são locais de deposição e reabsorção óssea que permitem ajustes no tamanho, forma e orientação das partes dos ossos do complexo craniofacial (Kokich, 1986).

O crescimento ósseo intramembranoso ocorre pela formação óssea no periósteo e nas suturas. As suturas, como maior ponto de expansão craniana durante o crescimento craniofacial pós-natal, precisam manter uma população de células indiferenciadas e outras em fase de diferenciação com deposição óssea, pois não apresentam um potencial de crescimento próprio, diferente da ossificação endocondral, que ocorre por um mecanismo de hipertrofia dos condrócitos. O estímulo para o crescimento ósseo sutural é coordenado pelas forças de crescimento do neurocrânio (Kokich, 1986; Opperman, 2000).

No crescimento do neurocrânio, o evento primário é a expansão volumétrica do cérebro, que também exerce efeito sobre o alongamento da base do crânio (Moss, 1975; Persson et al., 1979).

O crescimento encefálico exerce efeito sobre os ossos do crânio, gerando uma força biomecânica sobre a dura-máter, sobretudo nos locais de maior aderência dural. Na calota craniana, esta aderência está nas suturas e fontanelas; e na base do crânio encontra-se na crista galli, na asa menor do osso esfenoide bilateralmente, na crista da porção petrosa dos ossos temporais e no forame magno (Moss, 1975; McMaster, 1976). 
Destes pontos de aderência, originam-se os tratos das fibras durais orientados cranialmente, transmitindo as forças biomecânicas entre a base do crânio e a calota, controlando a deposição óssea normal nas maiores suturas da convexidade e direcionando os vetores do crescimento encefálico para assumir a forma hemisférica (Moss, 1975).

Dois princípios gerais estão envolvidos no crescimento craniofacial: deslocamento e remodelamento ósseo (Sven Kreiborg, 1986).

O remodelamento é produzido por atividade direta osteoblástica e osteoclástica, simultaneamente ao processo de deslocamento de todo o osso e ocorre continuamente nas superfícies ósseas interna e externa (Enlow, 1986).

Na calota craniana, um deslocamento marcado dos ossos frontal, parietal e occipital, com concomitante deposição óssea às margens das suturas, é característico no período do rápido crescimento cerebral. O tipo de deslocamento de crescimento depende da presença do funcionamento normal da sutura, atuando como área de crescimento e ajuste ósseo, enquanto o remodelamento feito pelo endocrânio e o ectocrânio serve para adaptar as alterações necessárias na curvatura individual dos ossos (Moss, 1975; Sven Kreiborg, 1986).

Nos primeiros anos de vida, o crescimento é extremamente rápido, mas tende a diminuir em torno dos 6 e 7 anos. Aos 5 anos de idade, 0 complexo crânio-órbito-zigomático é cerca de $85 \%$ do tamanho adulto. No 
entanto, pequenas alterações no crescimento sutural ocorrem na vida adulta (Waitzman et al., 1992b).

Na determinação da forma final do crânio, o tempo de cessação do crescimento do crânio é mais importante que o tempo de fusão das suturas (Hoyte, 1991).

\subsection{FISIOPATOLOGIA DA CRANIOSTENOSE}

A craniostenose é definida como o fechamento precoce de uma ou mais suturas cranianas (Cohen Jr, 1986; Persing, 2008), levando ao redirecionamento do crescimento craniofacial e à deformidade do crânio.

O fechamento precoce da sutura sagital leva à craniostenose mais comum, denominada escafocefalia. Observa-se um dismorfismo no neurocrânio caracterizado pelo crescimento anteroposterior, aumento da circunferência da cabeça, formação de uma crista óssea sobre a sutura sagital, estreitamento biparietal e bitemporal e proeminência frontal e occipital exagerada (Moss, 1975; Kaiser, 1988; Richtsmeier et al., 1991; DeLeon, et al., 2001; Aldridge el al., 2005; Schmelzer et al., 2007; Persing, 2008).

Sömmering (1800) apud Park e Robinson (2001) observa que o crescimento dos ossos da calota craniana ocorre especialmente às margens das linhas de sutura e que alterações nesse crescimento levariam a 
deformidades cranianas. Virchow (1851) apud Park e Robinson (2001), estudando essas deformidades, descreve a parada do crescimento dos ossos do crânio no sentido perpendicular à sutura fechada precocemente, com crescimento compensatório nas outras direções para acomodação do cérebro.

Apenas a sutura metópica fecha-se ainda na infância, em torno dos 3 anos de idade. As demais suturas iniciarão seu fechamento a partir dos 20 anos de idade (Kane, 2004). A maturação das suturas consiste no aumento das interdigitações e na substituição progressiva do tecido conjuntivo fibroso existente nos espaços entre os ossos por tecido ósseo.

$\mathrm{Na}$ craniostenose, ocorre a deposição óssea precoce nos espaços entre os ossos adjacentes, com perda da capacidade de crescimento do crânio na direção perpendicular à linha da sutura comprometida e com crescimento compensatório nos locais com as suturas patentes, conhecido como lei de Virchow (Cohen Jr, 1986; Kane, 2004).

A forma do crânio depende de qual sutura se fechou precocemente e em qual fase do crescimento isso ocorreu (Delashaw et al., 1991). A lei de Virchow estabelece os mecanismos de deformidade craniana, pela qual se pode aventar o formato do crânio conhecendo-se a sutura envolvida e viceversa.

Entretanto, as bases fisiopatológicas para a craniostenose primária não estão completamente esclarecidas. O crescimento do crânio 
perpendicular ao plano do fechamento precoce da sutura não explica todas as deformidades presentes na craniostenose (Park e Robinson, 2001).

Existem três teorias etiopatogênicas das craniostenoses: a que o fechamento precoce da sutura é o evento primário; a que alterações na base do crânio são o evento primário e a teoria da alteração do blastema mesenquimal, que acontece na craniostenose sindrômica (Cohen Jr, 1986; Williams et al., 1999).

Moss (1975) baseado em experimentos com animais, acompanhamento clínico e achados cirúrgicos, teoriza que a calota craniana, a dura-máter e a base do crânio formam uma entidade biomecânica, e que a alteração primária para a deformidade da calota craniana estaria na base do crânio. Na escafocefalia, a primeira modificação seria o fechamento precoce das porções laterais das sincondroses frontoesfenoidais, uma disostose do osso esfenoide, acarretando uma modificação espacial dos ossos da base do crânio, que alteraria as forças biomecânicas que se propagam da base para a convexidade pelos tratos de fibras durais, ocasionando o fechamento precoce da sutura sagital.

As forças biomecânicas transmitidas pela dura-máter causam alterações na ultraestrutura da morfologia da sutura, incluindo diminuição do tamanho das trabéculas ósseas, diminuição da densidade do osso mineralizado e o aumento do espaço medular na sutura sinostótica, com fechamento completo quando comparada à porção aberta da sutura sinostótica (Ozaki et al., 1998). 
Entretanto, Persson et al. (1979) em experimentos com animais, utilizam a restrição do crescimento de uma sutura causando deformidade da calota craniana, da base do crânio e da face e indicam que o fechamento precoce de uma sutura, por si só, é um fator causal na deformidade craniana observado nas craniostenoses.

Kohn (1994) descreve que o fechamento precoce de uma sutura tem um efeito bem localizado na calota craniana e não influencia a morfologia da base do crânio e da face.

Perlyn et al. (2001) avaliam o papel secundário das alterações da base do crânio na patogenia das craniostenoses. A cirurgia crânio-orbital em craniostenoses não sindrômicas e coronária bilateral parece induzir normalização da simetria endocraniana, sugerindo que o dismorfismo da base do crânio é uma manifestação secundária a uma alteração sutural.

Burke et al. (1995) descrevem que microespículas ósseas formam-se ao nível das suturas, criando pontes que unem as bordas ósseas. Não existe um mecanismo celular que remova essas pontes, pois não se encontra atividade osteoclástica, propondo que forças mecânicas normais, causadas pelo crescimento encefálico levam à fratura das microespículas. Nos pontos onde não ocorreu a fratura, existe o aumento da deposição óssea e fusão da sutura.

Os índices de formação óssea ao nível das suturas patológicas revelam uma atividade de maturação óssea muito elevada ao se comparar com as suturas normais (Ozaki et al., 1998). 
Aldridge et al. (2005) consideram que a fusão precoce da sutura é simplesmente uma ligação entre uma série de eventos complexos que resultam na craniostenose; que mutações genéticas não podem ser o único ou o fator primário para a craniostenose não sindrômica; que alterações no desenvolvimento cerebral, e não na formação óssea, podem estar presentes em certas craniostenoses e que a causa das craniostenoses não sindrômicas pode ser heterogênea.

Enquanto a mutação nos genes FGFR1-3 e TWIST são achados frequentes nas craniossinostoses sindrômicas, as mutações genéticas raramente são identificadas nas craniossinostoses não sindrômicas (Zeiger et al., 2002; Anderson et al., 2007). Existe associação familiar em 6\% dos casos, com transmissão autossômica dominante e penetrância reduzida em cerca de 38\% (Zeiger et al., 2002).

\subsection{AVALIAÇÃO RADIOLÓGICA}

Historicamente, o estudo radiológico simples do crânio era o exame subsidiário mais importante no diagnóstico e avaliação dos pacientes com escafocefalia.

$\mathrm{Na}$ radiografia em perfil do crânio, observa-se o alongamento anteroposterior do crânio, com crescimento anterior para baixo, e o espessamento da porção superoposterior do osso parietal, que corresponde ao ponto de fechamento precoce da sutura (Plese, 1980). 
Calcula-se também o ângulo basal de Welcher, formado pela intersecção da linha entre o násio e centro selar e a linha entre o centro selar e o básio. Os crânios com angulação da base normal têm o ângulo variando entre $120^{\circ}$ e $150^{\circ}$. Existe uma lordose basal, quando o ângulo é maior que $150^{\circ}$ e uma cifose basal, quando o ângulo é menor que $120^{\circ}$ (Wackenheim e Christmann, 1977; Smoker, 1994). O ângulo formado entre o plano clival e a fossa craniana anterior pode estar reduzido em $15^{\circ}$ ou mais abaixo da média, portanto, a cifose normal da calota craniana está acentuada na escafocefalia (David et al.,1982)

Na incidência anteroposterior e Towne há ausência da sutura sagital e observa-se a formação de uma ponte óssea; os ossos parietais estão verticalizados e o crânio com forma de ogiva.

Na incidência de Hitz, a base do crânio está alongada e estreita, relacionando essas alterações com o fechamento precoce das suturas frontoesfenoidais, parietoesfenoidais e temporoesfenoidais (Plese, 1980). A sela túrcica e a asa do esfenoide não são deformadas. Raramente as estruturas da face são afetadas (Fernbach e Naidich, 1986).

Atualmente, o exame de escolha na suspeita de craniostenose é a tomografia computadorizada de crânio com reconstrução em três dimensões (TC-3D) (Binaghi et al., 2000; Medina, 2000, Marcus et al., 2009).

Existem três razões para a realização da TC-3D: confirmar a hipótese clínica por identificação do fechamento da sutura; avaliar as possíveis anormalidades associadas, sobretudo nas craniostenoses sindrômicas e 
avaliar a extensão do comprometimento craniofacial (Persing, 2008; Freitas et al., 2010).

O uso da reconstrução em três dimensões tem mostrado um aumento na acurácia das medidas antropométricas quando comparadas às medidas realizadas em duas dimensões. Medidas em duas dimensões ainda poderão ser usadas clinicamente, mas não deverão ser usadas sozinhas para caracterizar as deformidades cranianas (Marcus et al., 2009; Heuzé et al., 2010).

Além da melhor avaliação da dolicocefalia do crânio na escafocefalia, para Furuya et al. (1984), a tomografia computadorizada demonstra as principais alterações focais observadas na calota craniana: a esclerose óssea parassutural, o aparecimento de uma crista óssea interna ou externa ao longo da sutura estenosada e um sulco profundo sobre o seio sagital superior.

Para avaliar as alterações morfológicas e o resultado do remodelamento cirúrgico pós-operatório, alguns índices são utilizados.

O índice craniano (IC) representa a razão entre a largura máxima pelo comprimento máximo do crânio.

A largura máxima é definida como a distância entre os eurions (EE), que são o ponto mais lateral em cada lado da cabeça. O comprimento máximo é a distância entre a glabela $(G)$ e ponto mais proeminente no occipício, denominado opistocrânio (O) (Cohen Jr., 1986; Farkas et al., 2003; Ruiz-Correa et al., 2006; Antúnez et al., 2009; Marcus et al, 2009). 
Crianças com escafocefalia, tipicamente, têm o IC de 60\% a 67\% (David e Simpson, 1982; Kaiser, 1988; Slomic et al.,1992; Kane, 2004), enquanto crianças com a forma normal do crânio têm IC de $76 \%$ a $78 \%$ (Slomic et al., 1992; Farkas et al., 1992; Farkas et al., 2003).

Os dados da Tabela 1 demonstram as variações do índice craniano, nas diferentes idades, após estudo de Farkas et al. (2003), com as medidas realizadas com o uso de paquímetro.

Marcus et al. (2009) estabelecem as variações do índice craniano em crianças com crânio normal, nas diferentes faixas etárias, pelas medidas realizadas pela TC-3D (Tabela 2).

Uma mínina discrepância entre as medidas diretas e indiretas da região craniofacial, distorção ou sobreposição de imagens e um grande número de pontos de referência revela que as imagens produzidas pela TC são confiáveis e precisas (Waitzman et al., 1992). 
Tabela 1 - Índice craniano (EE X 100/G-O)

\begin{tabular}{ccccc}
\hline \multirow{2}{*}{$\begin{array}{c}\text { Idade } \\
\text { (anos) }\end{array}$} & \multicolumn{2}{c}{ Masculino } & \multicolumn{3}{c}{ Feminino } \\
\cline { 2 - 5 } & Média & SD & Média & SD \\
\hline 1 & 74,5 & 3,8 & 75.6 & 4,1 \\
2 & 77,1 & 8,1 & 76.1 & 3,1 \\
3 & 75,4 & 2,8 & 75,6 & 2,8 \\
4 & 75.2 & 3,4 & 77,6 & 3,3 \\
5 & 76,7 & 3,6 & 75,8 & 2,9 \\
\hline
\end{tabular}

FONTE: Farkas LG, Hreczko TM, Katic MJ, Forrest CR. Proportion indices in the craniofacial regions of 284 healthy north americam white children between 1 and 5 years of age. $J$ Craniofac Surg. 2003;14(1):13-28. E: eurion; G: glabela; O: opistocrânio; SD: desvio padrão.

Tabela 2 - Índice craniano calculado pela tomografia de crânio, com reconstrução em três dimensões

\begin{tabular}{ccccc}
\hline \multirow{2}{*}{$\begin{array}{c}\text { Idade } \\
\text { (meses) }\end{array}$} & \multicolumn{2}{c}{ Masculino } & \multicolumn{2}{c}{ Feminino } \\
\cline { 2 - 5 } & Média & SD & Média & SD \\
\hline 1 & 83,4 & 3,44 & 81,7 & 2,89 \\
3 & 83,1 & 3,62 & 81,5 & 4,89 \\
6 & 81,7 & 2,39 & 83,7 & 5,49 \\
9 & 8,7 & 5,42 & 86,1 & 5,98 \\
12 & 80,9 & 4,99 & 82,4 & 7,79 \\
18 & 81,2 & 5,34 & 79,6 & 7,19 \\
24 & 79,1 & 5,81 & 77,7 & 6,09 \\
36 & 78,5 & 2,94 & 80,0 & 6,82 \\
48 & 78,6 & 5,41 & 80,6 & 6,80 \\
\hline
\end{tabular}

FONTE: Marcus JR, Domeshek LF, Loyd AM, Schoenleber JM, Das RR, Nightingale RW, Mukundan Jr S. use of a three-dimensional, normative database od pediatric craniofacial morphology for modern anthropometric analysis. Plast Reconstr Surg. 2009;124(6):2076-84. SD: desvio padrão. 
David et al. (2009), por meio da análise pré-operatória de TC-3D de pacientes com escafocefalia descrevem um sistema de classificação baseado nos achados anatômicos, e dividem as escafocefalias nos tipos anterior, central, posterior e complexo. No tipo anterior, embora o estreitamento do diâmetro biparietal seja bem descrito, existe um padrão significativo em que o estreitamento torna-se mais progressivo do vértice para a face posterior da parede lateral da órbita, eventualmente juntando-se com a base do crânio. No tipo central, não existem constricções nem bossa frontal significativa, a porção central da sutura é afetada, observa-se uma distribuição homogênea relativa da ossificação que, frequentemente, invade a metade posterior da fontanela anterior. No tipo posterior, o achado mais proeminente é a bossa occipital, podendo existir estreitamento biparietal posterior. No tipo complexo, não existe predominância de nenhuma das características da escafocefalia, podendo sugerir que a fusão da sutura ocorre em múltiplos locais simultaneamente.

Frente à variação na metodologia usada para determinar o maior comprimento e a maior largura do crânio com escafocefalia, Ruiz-Correa et al. (2006) desenvolvem quatro novos índices baseados no IC, estabelecendo relação entre a largura e o comprimento do crânio em diferentes planos de secção. O primeiro plano, denominado de plano S, é a projeção ao nível do inion do traçado entre a glabela e o meato acústico externo. Os demais planos são projeções a partir do plano da base do crânio, determinado pelo traçado entre a sutura nasal e o opístio: plano A, 
acima do topo dos ventrículos laterais; plano F, no forame de Monro; e plano M, ao nível da maior dimensão do quarto ventrículo (Figura 4).

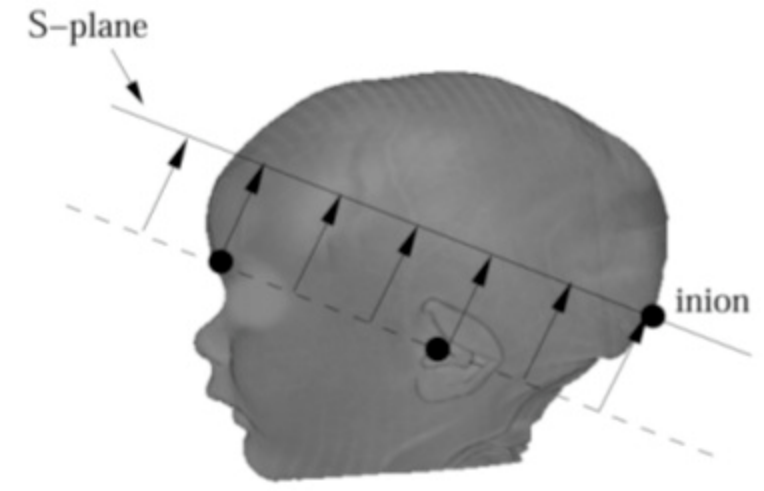

A

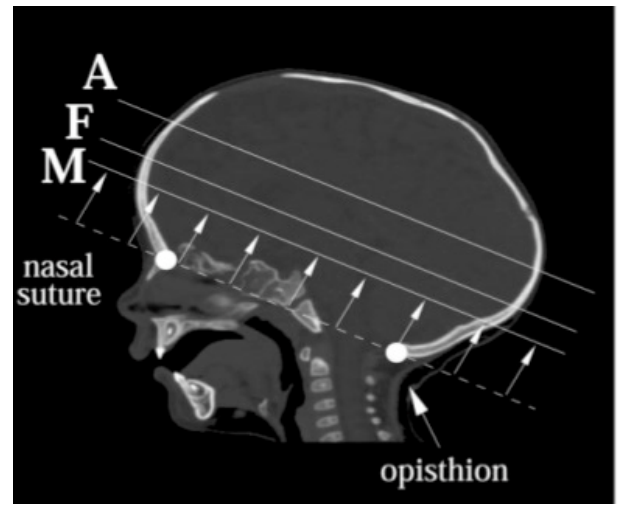

B

Figura 4 - Planos de secção na tomografia computadorizada. A: plano S projeção ao nível do inion do traçado entre a glabela e o meato acústico externo. B: planos A, F, M - projeções a partir do plano da base do crânio no topo dos ventrículos laterais, no forame de Monro e na maior dimensão do quarto ventrículo, respectivamente (FONTE: Ruiz-Correa S, Sze RW, Starr, JR et al. New Scaphocephaly Severity Indices of Sagittal Craniosynostosis: A Comparative Study With Cranial Index Quantifications. Cleft Palate Craniofac J. 2006; 43(2):211-21).

A TC-3D é um instrumento útil nas medidas da região craniofacial, complementando os métodos de tratamento, auxiliando no diagnóstico e avaliação da extensão e progressão do dismorfismo craniano, no planejamento e preparo cirúrgico e no seguimento dos pacientes. 


\subsection{PRINCÍPIOS DO TRATAMENTO CIRÚRGICO}

O primeiro relato de um procedimento cirúrgico para correção de craniostenose foi, em 1890, por Lannelongue. Em 1892, Lane descreve a primeira craniectomia linear com ressecção da sutura fechada. Nos últimos 30 anos, várias técnicas para correção da craniostenose têm sido aperfeiçoadas (Jane Jr et al., 2000; Clayman et al., 2007).

Os protocolos de tratamento recomendam a correção cirúrgica no $1^{\circ}$ ano de vida, para corrigir e prevenir danos cerebrais, aliviar um potencial aumento da pressão intracraniana (PIC), corrigir o dismorfismo e prevenir trauma psicológico que podem ocorrer nas crianças (DeLeon, 2001; Aldridge et al., 2005; Persing, 2008).

Por muitos anos, a indicação do tratamento cirúrgico da craniostenose sagital era simplesmente estético. Entretanto, a monitoração da PIC mostrou que $14 \%$ a $24 \%$ tinham aumento da PIC, e o uso da tomografia por emissão de prótons evidenciou que em $70 \%$ dos casos de escafocefalia havia redução do fluxo sanguíneo cortical na proximidade da sutura sinostótica (Mackenzie et al., 2009).

Embora muitos cirurgiões concordem que a correção cirúrgica após 1 ano de idade também tenha benefício, muitos têm optado pela realização da cirurgia, após o período de anemia fisiológica do lactente, ou seja, entre o $3^{\circ}$ e o $6^{\circ}$ mês de vida. Neste período, os ossos são maleáveis, podem ser cortados com facilidade e remodelados simplesmente por fratura tipo galho verde, além de ser o período de expansão cerebral rápida, o que facilitaria o 
crescimento e remodelamento da calota craniana (Massimi et al., 2007; Persing, 2008).

As características essenciais do tratamento cirúrgico da craniostenose são a remoção da sutura fechada, permitindo um crescimento e desenvolvimento craniano normal e o remodelamento dos ossos e das anormalidades compensatórias, evitando-se estados de hipertensão intracraniana e comprometimento neurocognitivo (Albright, 1985; Kane, 2004; Persing, 2008).

Nas cirurgias craniofaciais, a perda sanguínea ocorre pela duração da cirurgia e extensão das osteotomias (Mackenzie et al., 2009).

Jane e Persing (1986) descrevem cinco técnicas para a correção cirúrgica da escafocefalia: craniectomia linear envolvendo a sutura sagital (suturectomia); craniectomia linear paralela à sutura sagital bilateralmente; craniectomia ampla envolvendo a sutura sagital com extensão anterior e posterior; técnica de transposição dos ossos da calota craniana e a craniectomia em formato da letra grega $\mathrm{Pi}(\pi)$.

A técnica da craniectomia linear foi introduzida, em 1948, por Ingraham e Matson, com realização da suturectomia sagital, tornando-se um dos padrões na correção cirúrgica das escafocefalias (Jane e Persing, 1986; Willians et al., 1999), porém ela não altera diretamente as bossas frontal e occipital, nem corrige a deformidade subtemporal resultante da bossa frontal e da falta do crescimento lateral do osso parietal. 
A técnica de craniectomia ampla envolvendo a sutura sagital com extensão anterior, para a remoção da sutura coronária bilateral até a base do crânio, e extensão posterior pela sutura lambdóide até a sutura escamosa temporal foi descrita por Stein e Schut (1977). Estes autores relatam um resultado ótimo no remodelamento craniano em $96 \%$ das crianças tratadas com esta técnica, mas, em uma série de craniectomias lineares, o resultado foi bom em apenas um terço dos pacientes. Com esta técnica, propiciam uma desconexão eficiente entre a base e a calota craniana

A transposição dos ossos da calota craniana é usada, especialmente, para crianças com deformidade mais graves e nas crianças mais velhas (Jane e Persing, 1986).

Segundo Willians et al. (1999), a realização de craniectomia linear em crianças abaixo de 6 meses de idade com deformidade grave não foi satisfatória para correção da forma do crânio e, em crianças com mais de 2 anos de idade, houve necessidade de reconstrução de três quartos da calota.

Maugans et al. (1997) descrevem que o remodelamento da calota craniana leva à correção imediata e mais duradoura da forma do crânio na escafocefalia quando comparada à craniectomia linear.

Jane et al. (1978) descrevem um novo procedimento para correção de todas as deformidades na escafocefalia, denominado de craniectomia em formato de $\pi$, com a realização de uma craniotomia paralela à sutura sagital 
bilateral, iniciando posteriormente a sutura coronária e terminando anterior a sutura lambdoide, seguida da remoção da sutura coronária. Descola-se a dura-máter do osso frontal e da sutura sagital. Com o uso de fios, tracionase posteriormente o osso frontal até a banda óssea que permaneceu na linha média, para reduzir a bossa frontal e o comprimento do crânio. Seguese com o remodelamento dos fragmentos ósseos retirados primeiramente, diminuindo seus diâmetros, que são ancorados na dura-máter na região parietal. Quando o abaulamento occipital é mais importante, o que ocorre em $10 \%$ a $15 \%$ das escafocefalias, adapta-se a cirurgia para a região posterior do crânio. A retirada das suturas coronárias e a diminuição dinâmica do diâmetro anteroposterior provocam alterações nas forças biomecânicas da base do crânio, impedindo o fechamento precoce das novas suturas.

Nos casos onde as bossas frontal e occipital são muito proeminentes, realiza-se a remoção desses ossos e o remodelamento por osteotomias radiais (Jane Jr et al., 2000).

Smyth et al. (2006) descrevem uma técnica cirúrgica para correção da escafocefalia em crianças com mais de 1 ano de idade, onde a deformidade craniana já está bem instalada e a possibilidade de defeitos ósseos, após procedimentos mais agressivos, pode ocorrer por falha na reossificação. Consiste na realização de múltiplas osteotomias paralelas à sutura coronária, tipo aduelas de barril, para ampliar a constricção biparietal, seguidas de craniotomia bifrontal com remodelamento e osteotomias radiais no osso occipital, permitindo uma menor ressecção óssea. 
Recentemente, com o advento da endoscopia, as atenções têm se voltado à realização da craniectomia linear endoscópica, técnica inicialmente descrita por Jimenez e Barone, em 1998, oferecendo a vantagem de redução do tempo cirúrgico, cirurgia segura, redução dos custos, redução do tempo de internação e redução da perda de sangue. A crítica a esta técnica é a menor exposição e controle do seio sagital superior, e a necessidade do uso de órteses cranianas no pós-operatório para auxiliar o remodelamento do crânio (Clayman et al., 2007; Greensmith et al., 2008).

O uso do endoscópio para realização da craniectomia linear tem indicação em crianças com idade inferior a 3 meses e com pouca deformidade da calota craniana (Persing, 2008).

O rápido crescimento ósseo que se verifica nas áreas de craniectomia é responsável pela reossificação e pela possibilidade de resultados cirúrgicos insatisfatórios (Plese, 1980). Para impedir a rápida proliferação óssea, algumas técnicas usam a interposição de materiais cirúrgicos nas bordas da craniectomia, como placas bioabsorvíveis e molas, permitindo um remodelamento dinâmico e uma correção gradual da escafocefalia (Mackenzie et al., 2009).

A escolha da técnica e suas variações deve ser direcionada para cada paciente, frente à deformidade craniana, além da preferência pessoal do cirurgião (Jane e Persing, 1986; Clayman et al., 2007). 
2 OBJETIVOS 
Realizar medidas antropométricas da base do crânio em crianças com escafocefalia, analisando qual a influência da correção cirúrgica no remodelamento da base do crânio e nas alterações das medidas antropométricas, e se existe uma relação entre o remodelamento da calota craniana e o remodelamento da base do crânio. 
3 MÉTODOS 
Entre o período de abril de 2007 a dezembro de 2008 foram operadas 21 crianças com diagnóstico de escafocefalia, sendo 19 delas matriculadas no ambulatório de Neurocirurgia Pediátrica do Hospital das Clínicas da Faculdade de Medicina da Universidade de São Paulo e duas da clínica privada, que foram operadas no Hospital Sírio-Libanês em São Paulo.

O anexo A (Tabela 7) mostra a identificação dos pacientes, sexo, número de registro hospitalar, data de nascimento, idade na cirurgia e data da cirurgia.

Todas as crianças já foram encaminhadas para avaliação neurocirúrgica com o diagnóstico clínico e/ou radiológico de escafocefalia.

Os familiares foram comunicados sobre o estudo, concordando participar dele, autorizando a inclusão de seus filhos e o uso das imagens pré, intra e pós-operatórias, após assinatura do Termo de Consentimento Livre e Esclarecido aprovado pela Comissão de Ética para Análise de Projetos de Pesquisa - CAPPesq- da Diretoria Clínica do Hospital das Clínicas e da Faculdade de Medicina da Universidade de São Paulo (Anexos B e C).

Ao exame clínico, as crianças apresentavam as características típicas da escafocefalia, com alongamento anteroposterior do crânio e proeminência na região frontal e occipital na avaliação em perfil (Figura 5). 
De frente, observava-se um crânio alto, com estreitamento laterolateral (Figura 6); em uma visão superior, o crânio alongado e estreito, mais globoso na região frontal e mais afilado na região occipital (Figura 7).

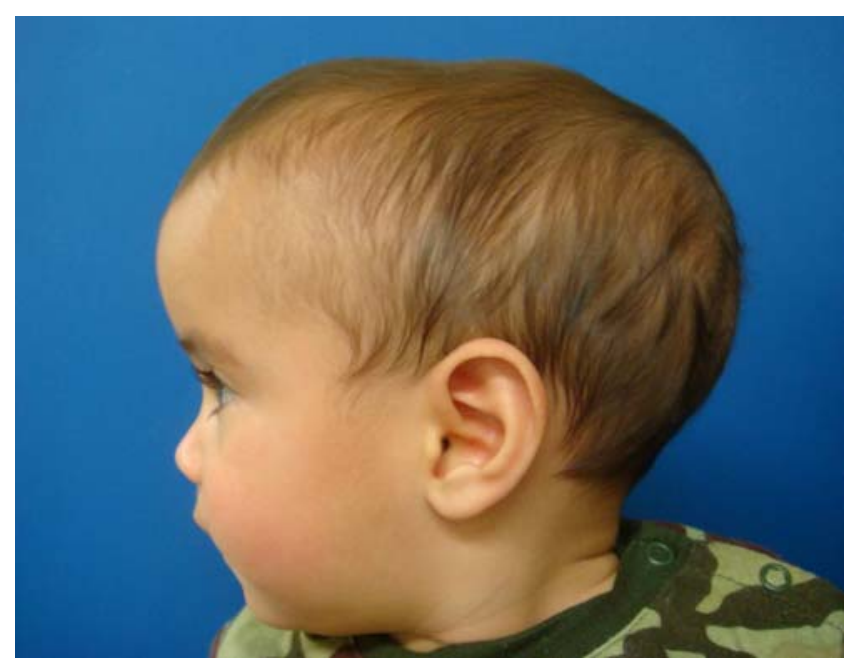

Figura 5 - Fotografia pré-operatória em perfil do paciente MNF. Observase o alongamento anteroposterior do crânio, o estreitamento laterolateral e as proeminências frontal e occipital

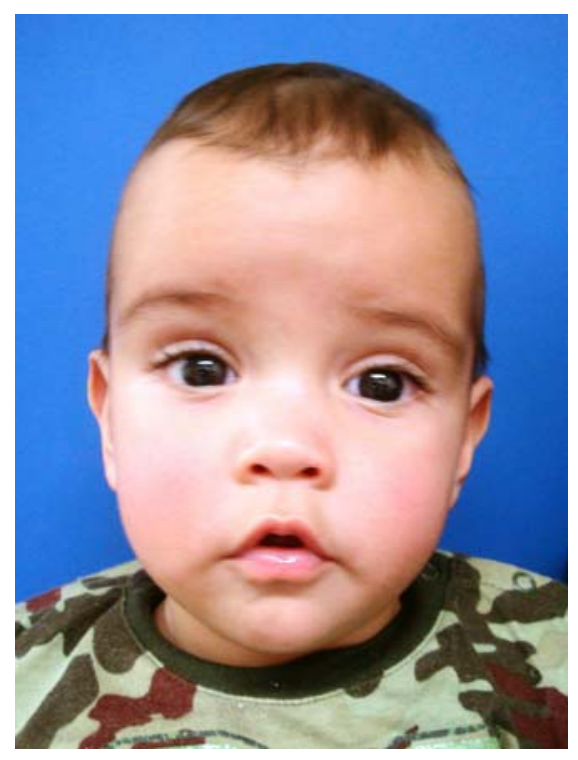

Figura 6 - Fotografia pré-operatória com visão anterior do paciente MNF. Observa-se um crânio alto, estreito e abaulamento na região frontal 


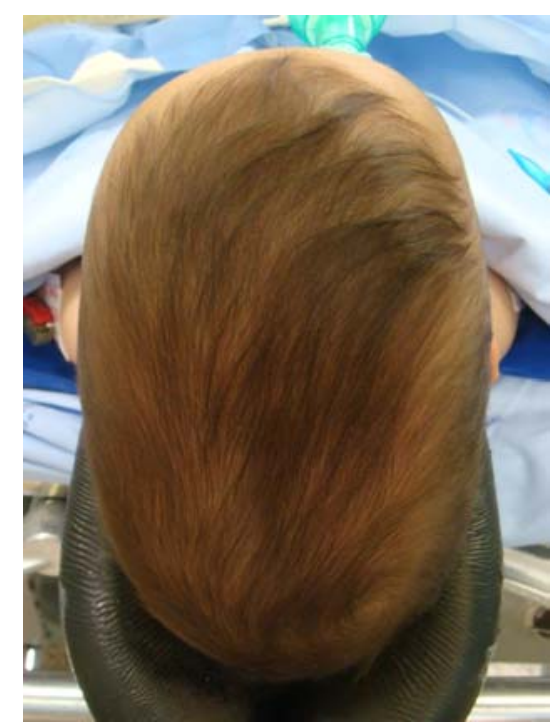

Figura 7 - Fotografia pré-operatória com visão superior do paciente MNF. Observa-se o alongamento e estreitamento do crânio, a região frontal globosa e a região occipital afilada

O exame neurológico era dentro dos limites da normalidade em todas as crianças, com desenvolvimento neuropsicomotor adequados à idade.

No atendimento inicial, foram realizadas as medidas da distância anteroposterior (AP) e da distância biauricular (BA), usando uma fita métrica. A distância anteroposterior mede-se da glabela até a proeminência occipital externa, seguindo a convexidade pela sutura sagital superior. A distância biauricular mede-se da inserção superior de uma orelha à outra, seguindo a convexidade pela sutura coronária (Diament, 2005).

A confirmação diagnóstica foi realizada com a TC-3D, avaliando-se 0 fechamento precoce da sutura e o grau de deformidade da calota craniana (Figura 8). As imagens foram obtidas por uma tomografia computadorizada helicoidal da base do crânio até o vértice em máquinas modelo General 
Eletrics Hi-Speed Advantage Spiral Computed Tomography, com cortes que tiveram um intervalo variando de $1,25 \mathrm{~mm}$ a $2 \mathrm{~mm}$. As imagens foram gravadas em formato DICOM (Digital Imaging and Communications in Medicine).

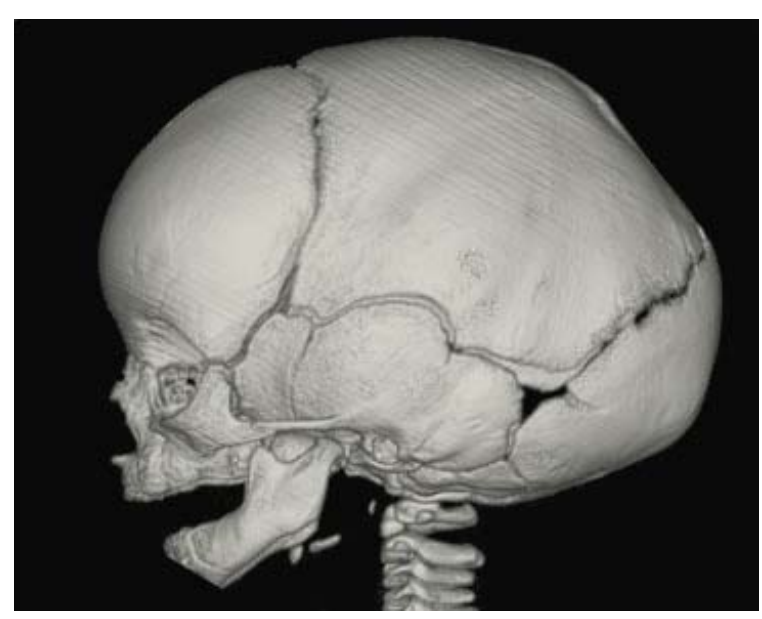

a

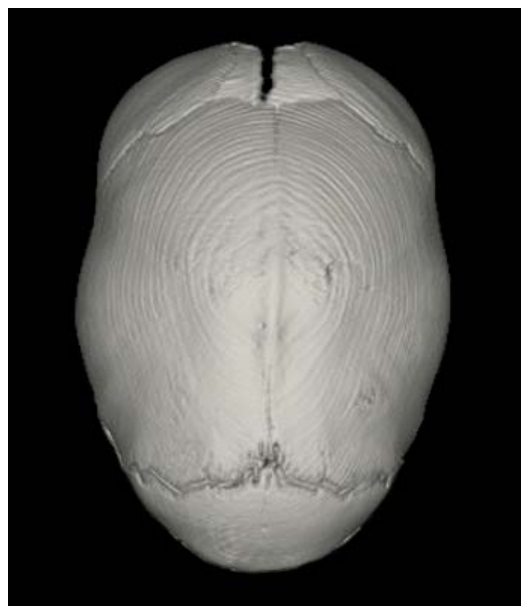

b

Figura 8 - Tomografia computadorizada de crânio com reconstrução em três dimensões do paciente JVDN. a) Observa-se o alongamento anteroposterior; b) Observa-se o fechamento da sutura sagital superior, o estreitamento laterolateral do crânio e as bossas frontal e occipital

$\mathrm{Na}$ internação hospitalar e após 1 ano do tratamento cirúrgico, as medidas do crânio com a fita métrica eram novamente realizadas, e esses valores foram os usados para avaliação e comparação pós-operatória, realizando-se o índice encefálico modificado, proposto por Diament (2005) que é o quociente da distância biauricular sobre a distância anteroposterior. 
Todas as crianças foram submetidas à anestesia geral (endovenosa e inalatória) por anestesiologista com prática em pacientes pediátricos. Apenas em uma criança não houve reposição de hemoderivado em nenhuma fase de sua internação hospitalar, por motivos religiosos familiares e pela opção da equipe cirúrgica em respeitar esta decisão. Todas os demais pacientes receberam transfusão sanguínea no intraoperatório e não necessitaram de nova transfusão no pós-operatório.

O posicionamento cirúrgico foi em decúbito dorsal, com a cabeça apoiada pela região suboccipital em uma cabeceira cirúrgica em forma de ferradura, em ligeira flexão. Era confirmada com o anestesiologista se a posição não comprometia a ventilação mecânica e poderia proporcionar certo grau de movimentação da cabeça sem riscos para a intubação (Figura 9).

A tricotomia do couro cabeludo baseou-se na vontade dos pais, tendo a maioria optado pela tricotomia total. Nas outras, foi realizada a tricotomia apenas em uma faixa possibilitando a marcação e a abertura da pele.

A incisão do couro cabeludo adotada foi em forma de zigue-zague da inserção de um pavilhão auricular ao outro (Figura 10), posteriormente à linha de implantação do cabelo. 


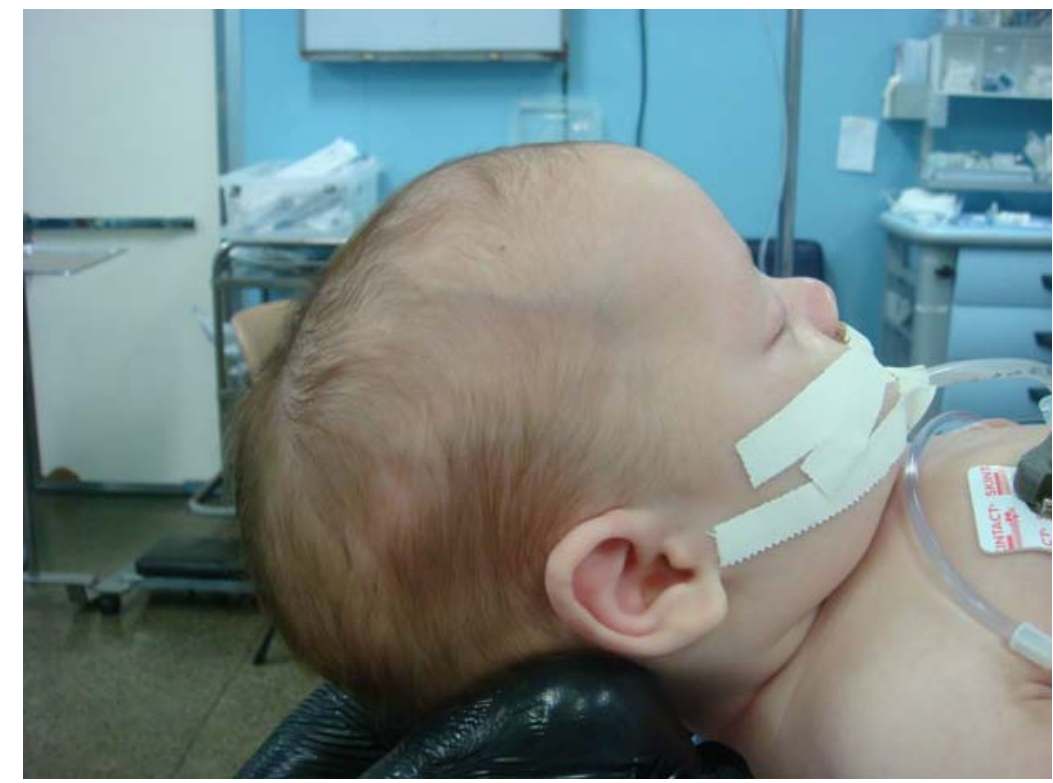

Figura 9 - Fotografia intraoperatória do paciente LFCB, mostrando o posicionamento da cabeça para a cirurgia. Observa-se a cabeça apoiada pela região suboccipital e em ligeira flexão

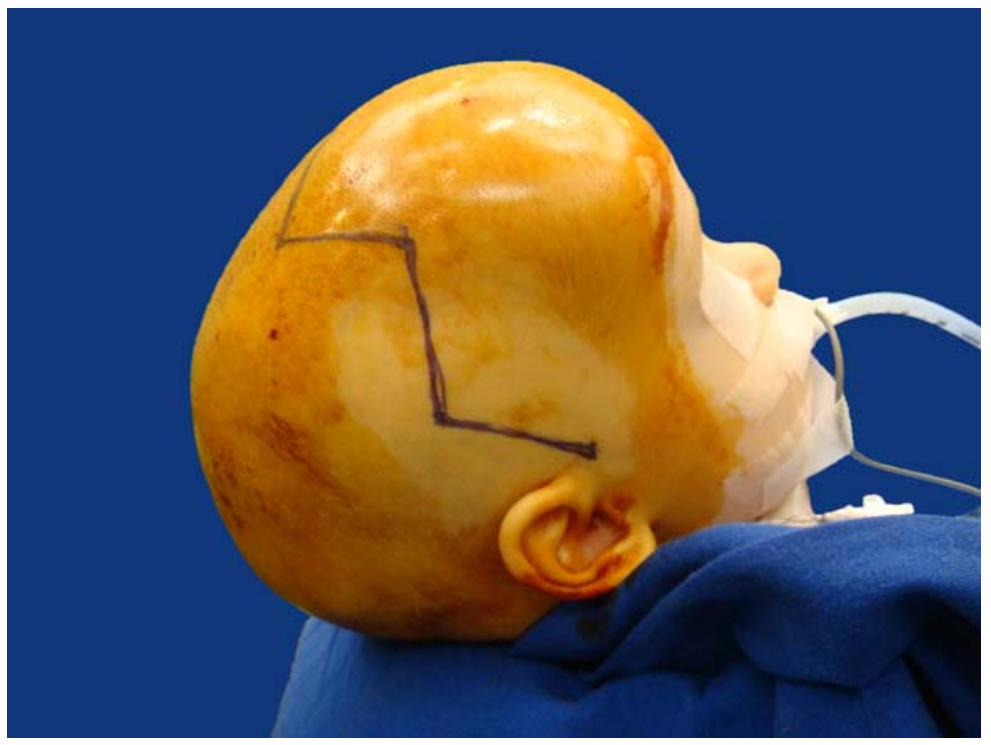

Figura 10 - Fotografia intraoperatória do paciente LEA, mostrando a marcação da incisão no couro cabeludo em zigue-zague. A incisão inicia-se na inserção do pavilhão auricular de um lado até o outro 
A incisão foi infiltrada em toda a sua extensão com solução de adrenalina para se diminuir a perda sanguínea durante a abertura do couro cabeludo.

Seguidos à abertura do couro cabeludo, os retalhos cutâneos foram rebatidos anteriormente até o rebordo orbitário e, posteriormente, até a exposição da bossa occipital, sempre com cuidadosa hemostasia do couro cabeludo e da superfície óssea em exposição (Figura 11).

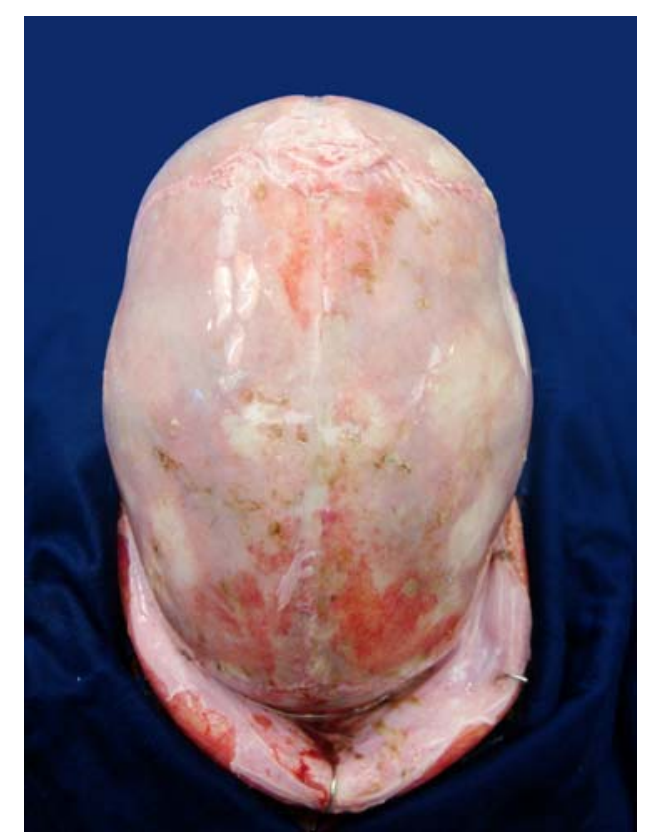

Figura 11 - Fotografia intraoperatória do paciente LEA, mostrando a exposição de toda a calota craniana. Observa-se o fechamento da sutura sagital

A decisão da técnica cirúrgica utilizada para o remodelamento do crânio, baseou-se na idade da criança no momento da cirurgia e no grau de deformidade craniana. 
Nas crianças abaixo de 1 ano de idade, foi utilizada a craniectomia ampla, envolvendo a sutura sagital, a sutura coronária bilateral e a sutura lambdoide bilateral, conforme descrito por Stein e Schut (1977) e Plese (1980), seguida do remodelamento frontal e occipital e realização de osteotomias no retalho ósseo parietotemporal.

Iniciou-se com as trepanações, em torno de 16 orifícios, localizados quatro na linha mediana anterior no encontro da sutura sagital com a sutura coronária; quatro na linha mediana posterior no encontro da sutura sagital com a sutura lambdoide. Duas trepanações na região temporal anterior, na situação de encontro da sutura coronária com a sutura escamosa. E duas trepanações na região temporal posterior no encontro da sutura lambdoide com a sutura escamosa (Figura 12).

Os pontos de trepanação foram unidos com o uso do craniótomo após descolamento cuidadoso da dura-máter. Realizou-se a suturectomia coronária, seguida da suturectomia sagital com 2 centímetros laterais à sutura sagital fechada, bilateral. Posteriormente, realizou-se a suturectomia lambdoide (Figura 13).

Após as suturectomias, fez-se o remodelamento frontal por meio de craniotomia bifrontal, ressecção da porção óssea inferior até a bossa e osteotomias quando necessário. O retalho ósseo frontal foi fixado ao rebordo orbitário com fio de sutura vicril 2.0 ou com miniplaca absorvível (Figura 14).

Para o remodelamento occipital, foram feitas osteotomias radiais das bordas da ressecção óssea para a linha mediana. 
Nos retalhos ósseos parietotemporal bilaterais, foram realizadas osteotomias paralelas à borda da neossutura sagital (Figura 15).

No intraoperatório, observou-se uma acomodação do cérebro e um alargamento laterolateral do crânio.

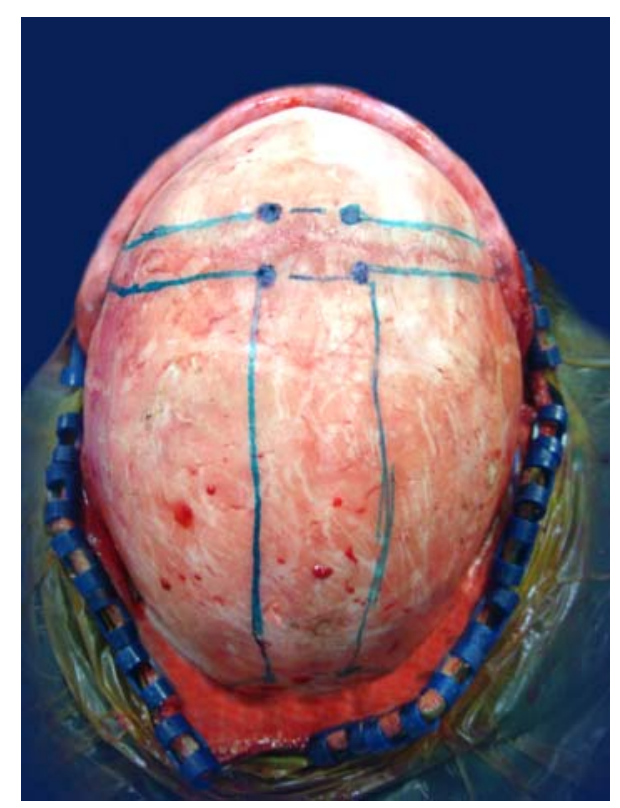

Figura 12 - Fotografia intraoperatória do paciente GCS. Visão superior da calota craniana com as marcações das trepanações medianas anteriores e das linhas da craniectomia 


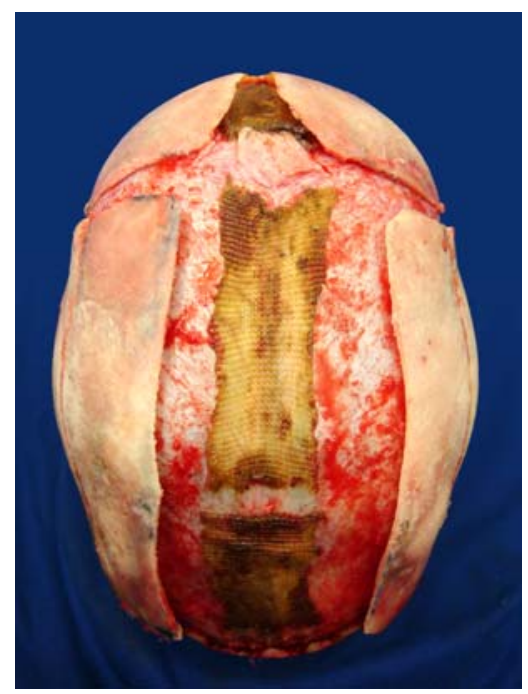

Figura 13 - Fotografia intraoperatória do paciente LEA. Visão superior após a realização das suturectomias. Sobre o seio sagital superior colocou-se celulose oxidada para hemostasia. Observa-se a expansão laterolateral do crânio

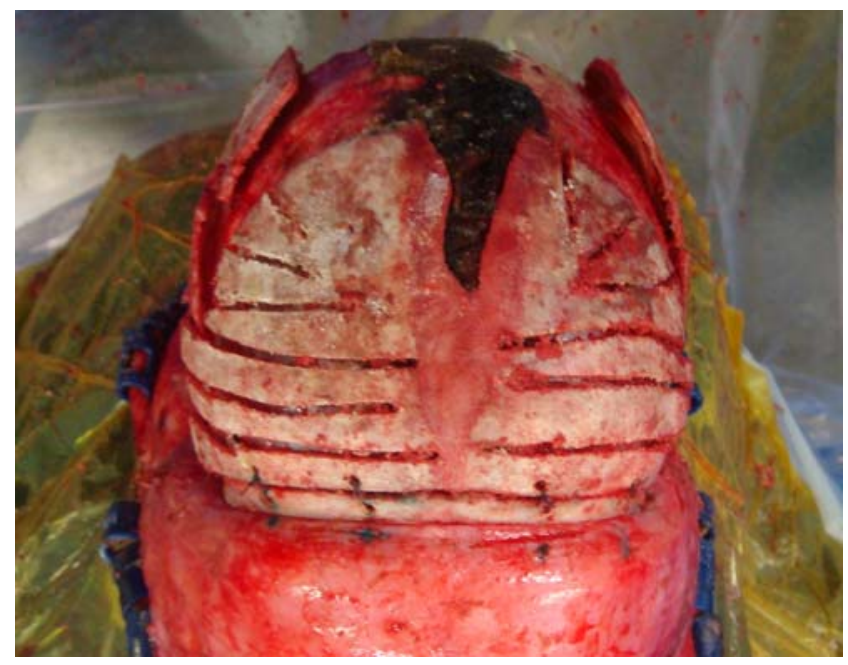

Figura 14 - Fotografia intraoperatória do paciente JVSS. Visão anterior, mostrando as osteotomias para o remodelamento frontal e a fixação no rebordo orbitário 


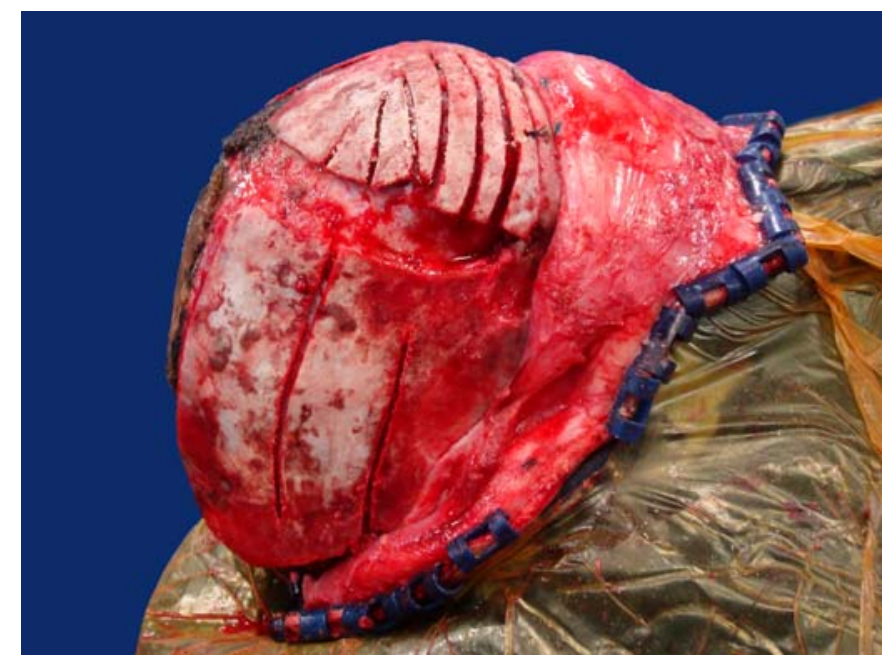

Figura 15 - Fotografia intraoperatória do paciente JVSS. Visão lateral ao final da cirurgia, com as osteotomias no retalho ósseo parietotemporal e o remodelamento do osso frontal

Nas crianças com mais de 1 ano de idade, seguiu-se a técnica descrita por Smyth et al. (2006). Após a exposição da calota craniana, fez-se a marcação das linhas para realização das osteotomias (Figura 16). Primeiro, realizou-se a craniotomia bifrontal com o limite anterior no rebordo orbitário e o superior na sutura coronária, deixando o remodelamento do osso frontal para o tempo final.

A partir da borda da craniotomia bifrontal, realizaram-se múltiplas osteotomias paralelas à sutura coronária, até a sutura lambdoide, com 2 centímetros de largura cada uma, estendendo-se desde o osso temporal inferior à sutura escamosa de um lado a outro da calota craniana (Figura 17).

O descolamento e a hemostasia da dura-máter eram realizados, à medida que se faziam as osteotomias. 


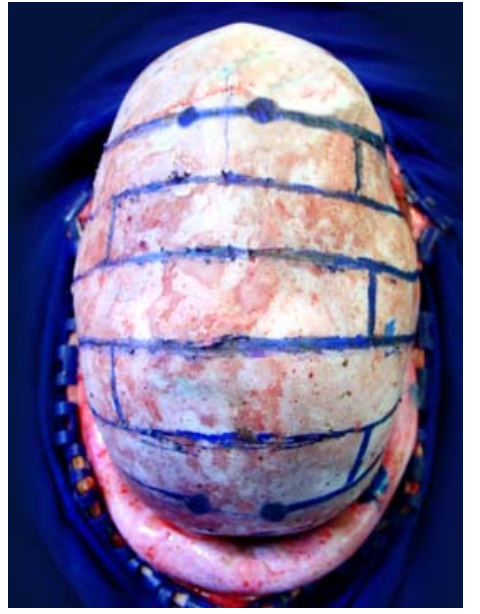

a

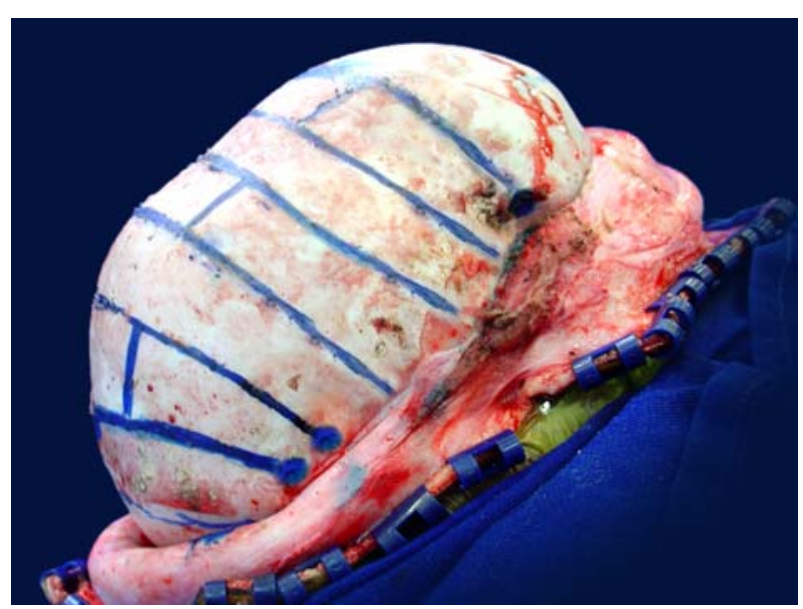

b

Figura 16 - Fotografia intraoperatória do paciente VGGC. Marcação das trepanações e linhas das osteotomias. a) visão superior; b) visão lateral direita

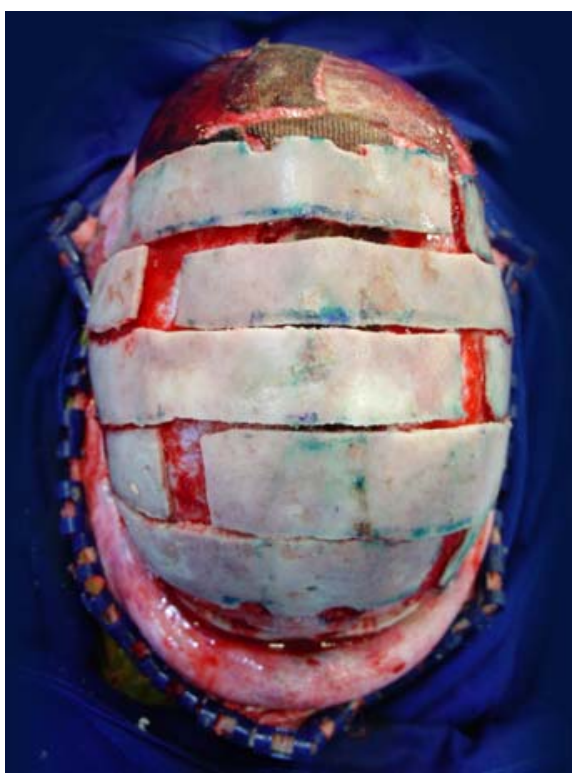

Figura 17 - Fotografia intraoperatória do paciente VGGC. Visão superior, após a realização da craniotomia bifrontal e das osteotomias tipo aduelas de barril. Observa-se a expansão do crânio pelo afastamento nas linhas das osteotomias 
Fez-se o remodelamento occipital por osteotomias radiais e o remodelamento frontal com ressecção óssea até a protuberância frontal e osteotomias na porção superior do retalho ósseo.

Ao final da cirurgia, os retalhos ósseos foram fixados com fio vicril 2.0 ou miniplacas absorvíveis, fazendo-se o remodelamento da calota craniana. Nos locais com falhas ósseas extensas, colocaram-se os fragmentos ósseos restantes do remodelamento frontal (Figura 18).

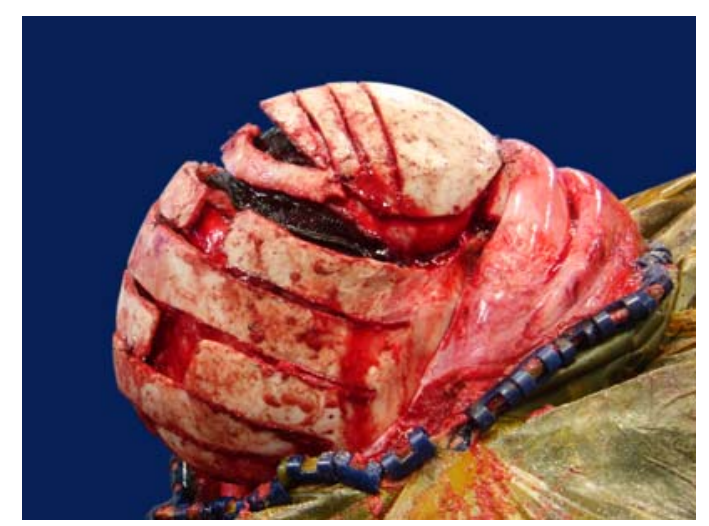

a

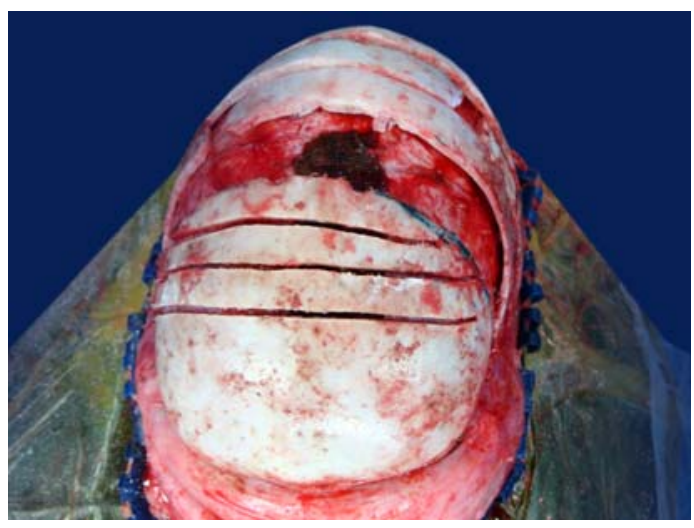

b

Figura 18 - Fotografia intraoperatória do paciente VGGC. Resultado cirúrgico final. a) Visão lateral direita; b) Visão anterior do remodelamento frontal

O fechamento do couro cabeludo foi feito como de rotina nas craniotomias, com colocação de dreno subgaleal com vácuo e uso de fio monocryl 3.0 para o fechamento do subcutâneo e de fio de nylon 4.0 para o fechamento da pele. 
O período de internação pós-operatória variou de 4 a 5 dias, dependendo da recuperação de cada criança.

As crianças mantiveram acompanhamento médico regular no ambulatório ou no consultório particular.

Após 1 ano do tratamento cirúrgico, foi realizada novamente uma TC3D com as mesmas especificações que o exame pré-operatório.

Com os exames pré e pós-operatórios, as imagens foram reconstruídas com auxílio do software OxiriX ${ }^{\circledR}$ para plataforma Mackintosh (Mac OS X), sendo realizadas as medidas nas imagens, antes e após 1 ano da correção, comparando-se os resultados entre si.

As medidas utilizadas foram:

- comprimento do crânio: distância máxima entre a glabela e a proeminência occipital, o opistocrânio, em um plano horizontal, denominado de GO (Figura 19);

- largura do crânio: distância máxima entre os pontos mais laterais do crânio, os eurions, denominados de EE (Figura 20);

- distância entre o início da crista galli e o tubérculo selar, denominado CG-TS (Figura 21);

- distância entre o início da crista galli e o meato acústico interno direito, denominado CG-MAI (Figura 22);

- distância entre os meatos acústicos internos, denominados MAIMAI (Figura 23); 
- distância entre os forames ovais, denominados FO-FO (Figura 24);

- ângulo da base do crânio: medida do ângulo formado entre o násio, o centro da sela túrcica e o básio, denominado Â1 (Figura 25);

- ângulo formado entre o násio, o centro da sela túrcica e o opístio, denominado Â2 (Figura 26).

Com os resultados do comprimento e largura do crânio, foram calculados o índices cranianos (IC) pré-operatório e no pós-operatório tardio de 1 ano.

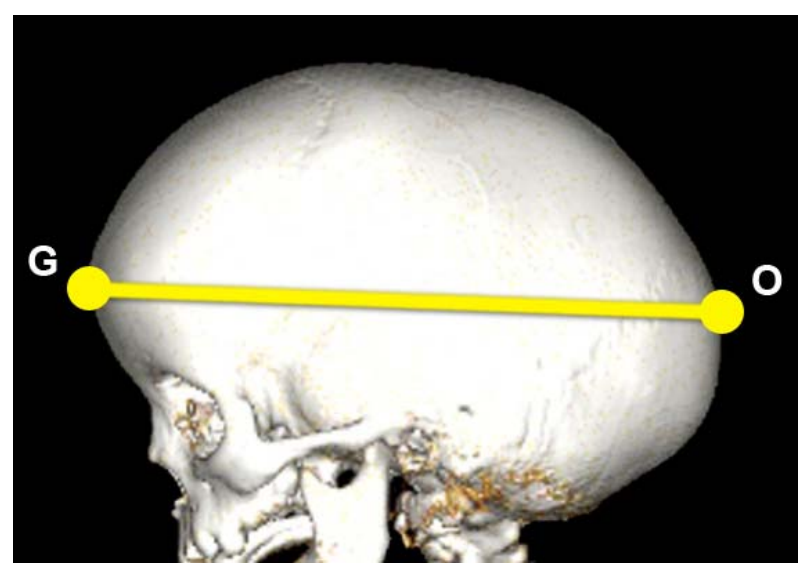

Figura 19 - Comprimento do crânio - Distância entre a glabela (G) e 0 opistocrânio (O). Tomografia computadorizada com reconstrução em três dimensões do paciente VZM 


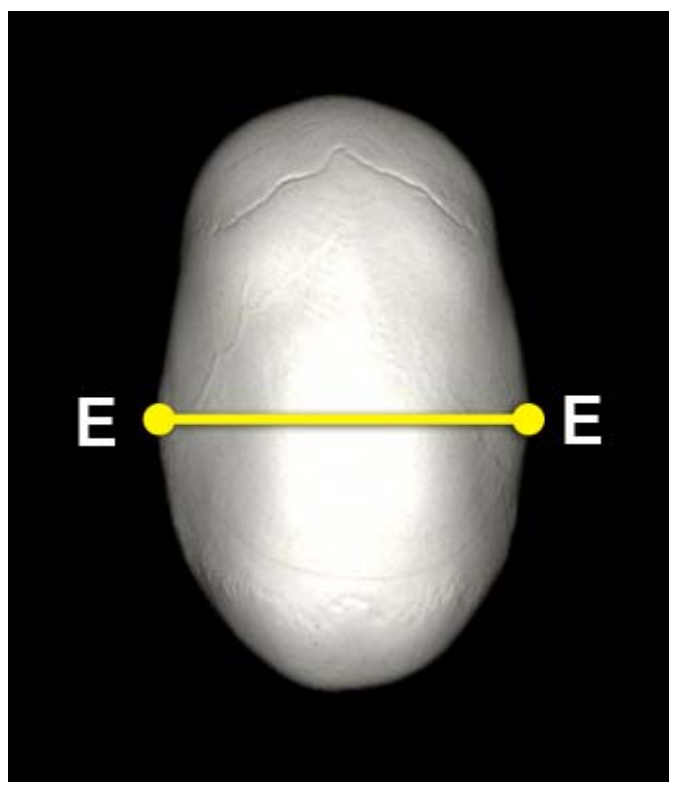

Figura 20 - Largura do crânio - Distância entre os eurions (EE). Tomografia computadorizada com reconstrução em três dimensões do paciente VZM

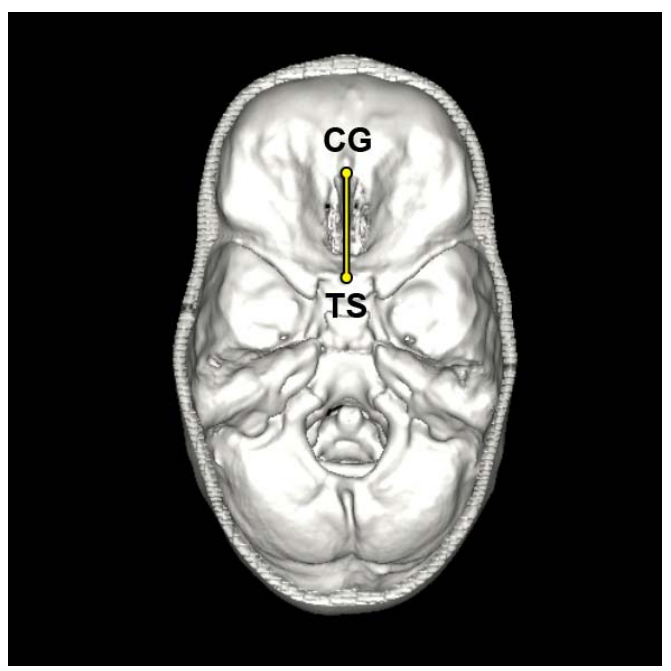

Figura 21 - Distância entre o início da crista galli (CG) e o tubérculo selar (TS). Tomografia computadorizada com reconstrução em três dimensões do paciente VZM 


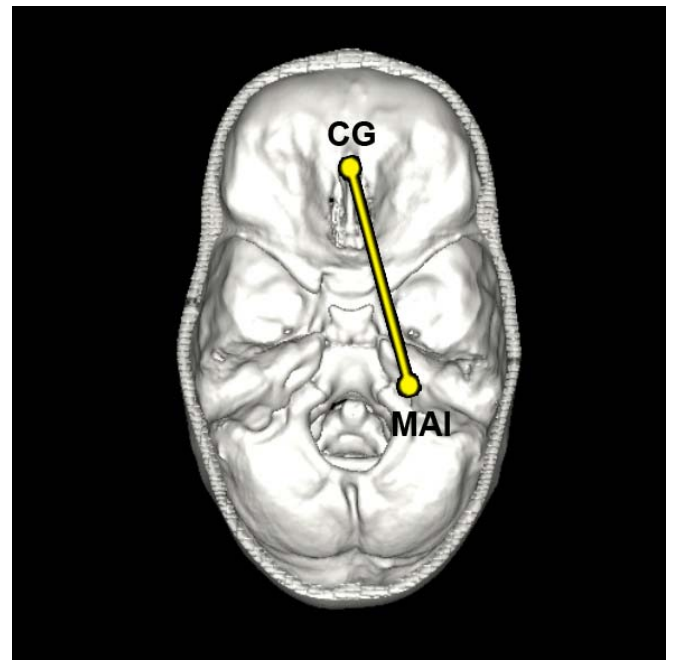

Figura 22 - Distância entre a crista galli (CG) e o meato acústico interno (MAI). Tomografia computadorizada com reconstrução em três dimensões do paciente VZM

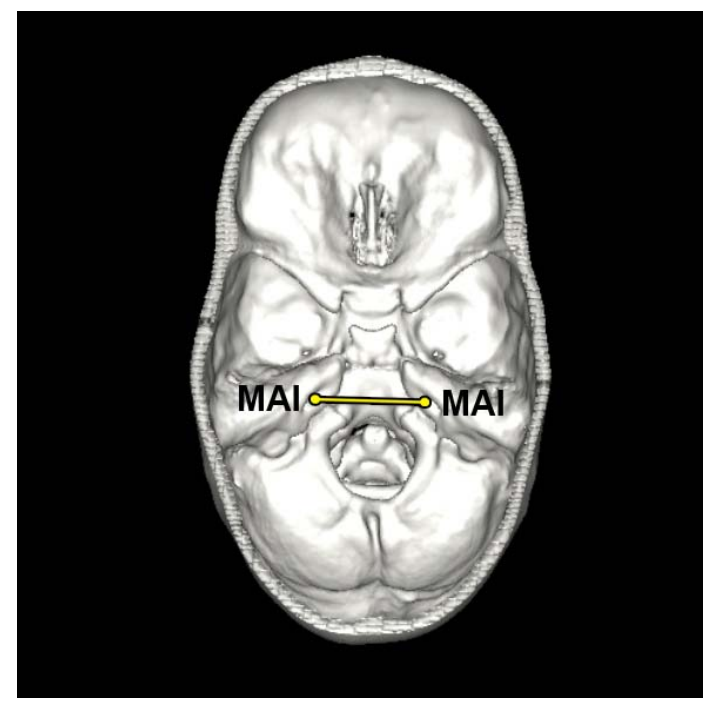

Figura 23 - Distância entre os meatos acústicos internos (MAI-MAI). Tomografia computadorizada com reconstrução em três dimensões do paciente VZM 


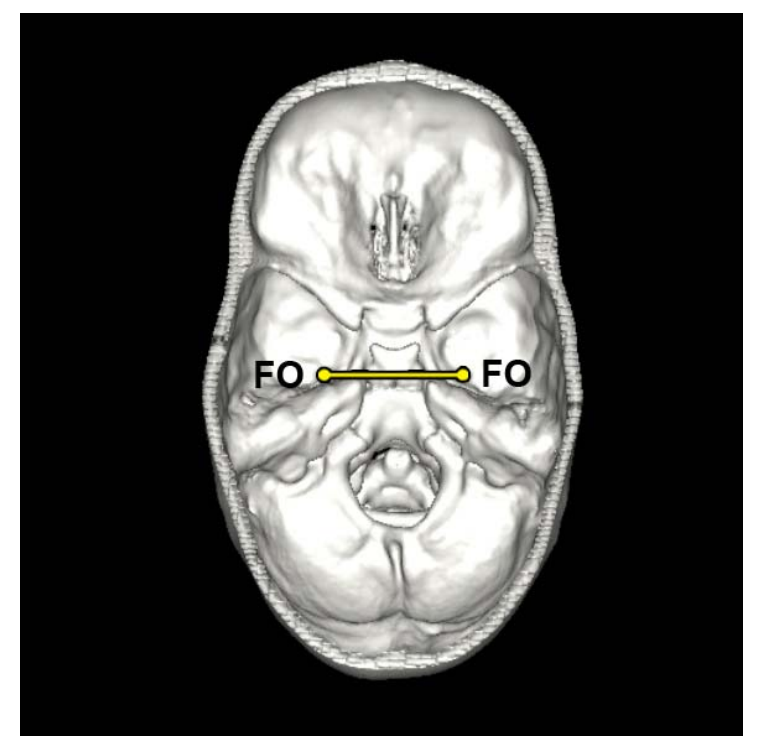

Figura 24 - Distância entre os forames ovais (FO-FO). Tomografia computadorizada com reconstrução em três dimensões do paciente VZM

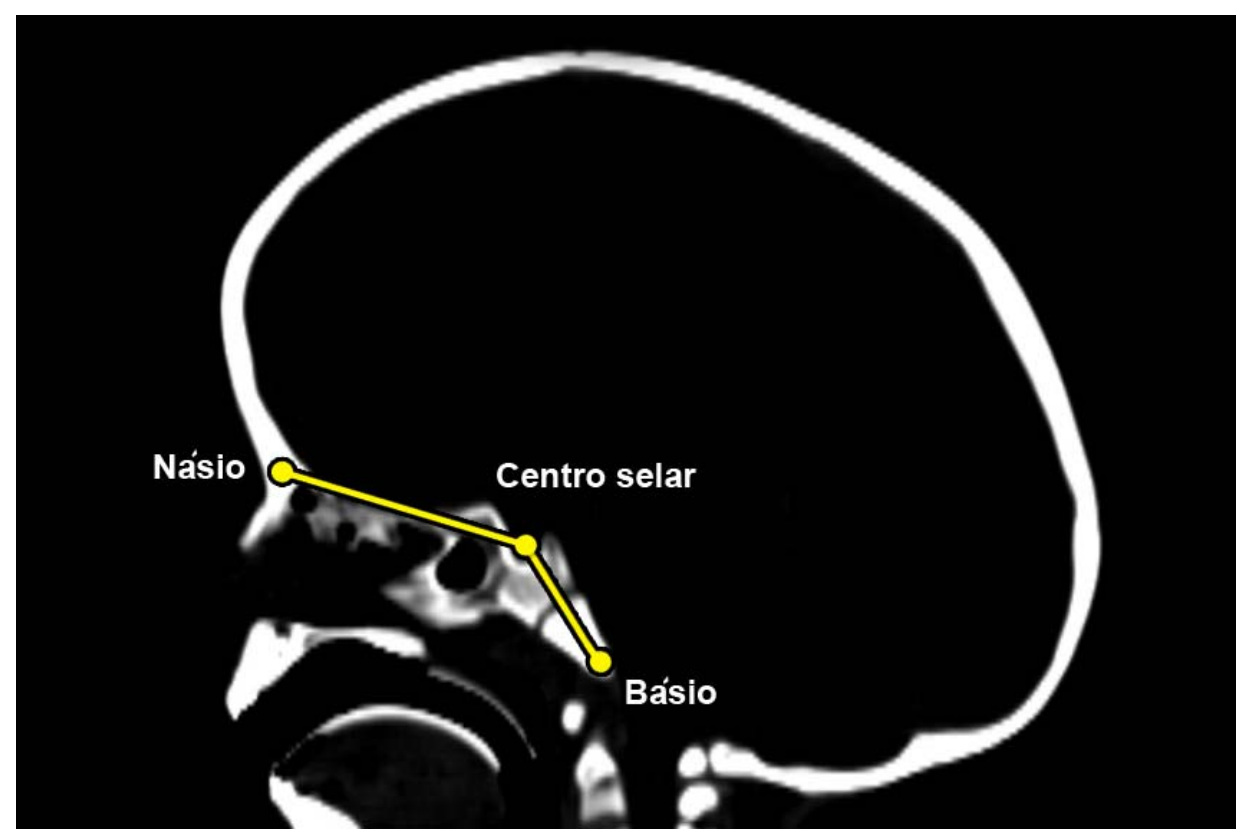

Figura 25 - Ângulo da base do crânio (Â1), formado entre o násio, o centro selar e o básio. Tomografia computadorizada do paciente VZM 


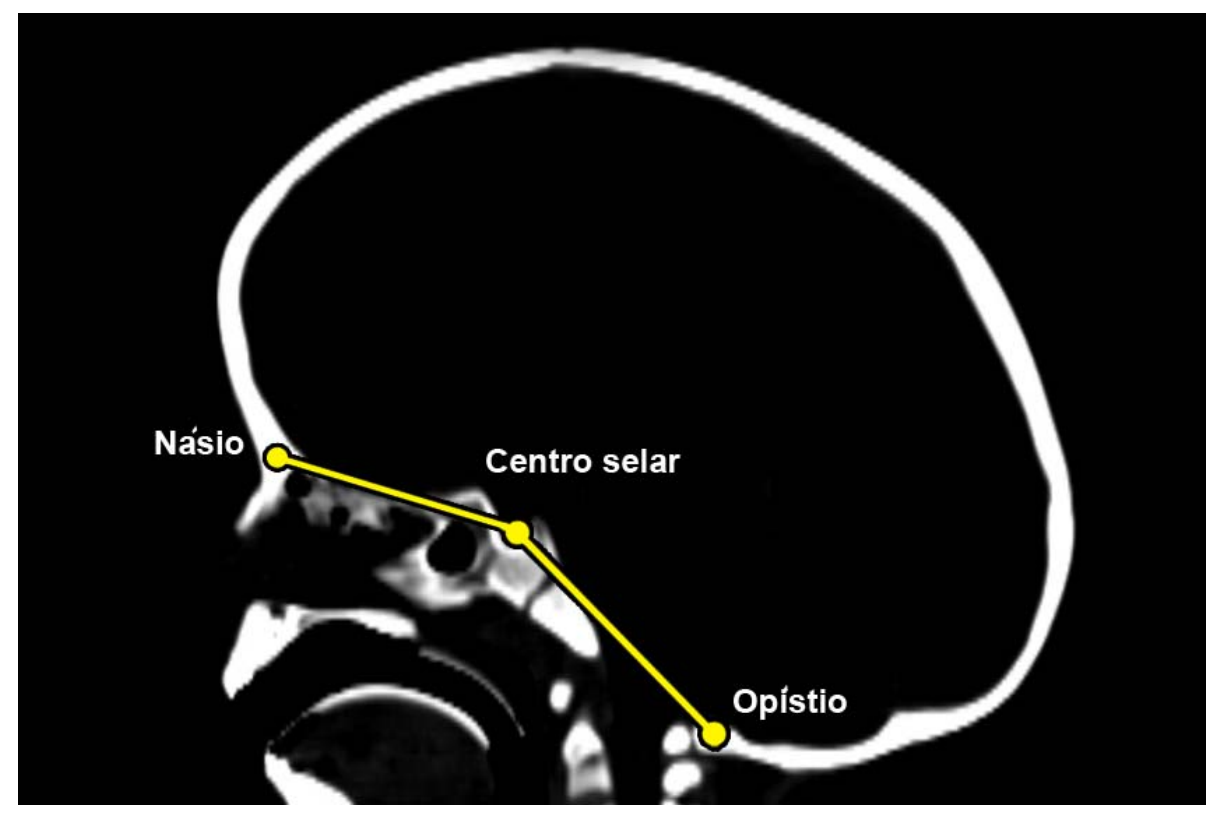

Figura 26 - Ângulo formado entre o násio, o centro selar e o opístio (Â2). Tomografia computadorizada do paciente VZM

O anexo D (Tabela 8) mostra os resultados de todas as medidas antropométricas realizadas, antes e após o tratamento cirúrgico.

Para a análise estatística, foram utilizados os testes de hipótese para a diferença entre duas medidas com variâncias estimadas, o Teste $t$ (student), que comparou as medidas pré-operatórias com as medidas pósoperatórias. Adotou-se um valor de $p<0,01$, como sendo valor estatisticamente significativo.

Foram operadas 16 crianças do sexo masculino e 5 do sexo feminino. A idade no dia da cirurgia variou de 2,4 meses a 29,6 meses, com média de 11,3 meses. 
Pela técnica usada para o tratamento cirúrgico, as crianças foram divididas em dois grupos: abaixo de 1 ano de idade, 14 crianças, e acima de 1 ano de idade, sete crianças.

No pós-operatório, perdeu-se o seguimento de dois pacientes, VMS 26m19d e YCO 8m25d, permanecendo 19 crianças para análise dos resultados.

A mortalidade cirúrgica nesta série foi zero.

As complicações intraoperatórias foram praticamente inexistentes, exceto por uma pequena laceração na borda do seio transverso esquerdo do paciente VMS, que foi tamponada com celulose oxidada, sem interferências na cirurgia ou na evolução pós-operatória e neurológica do paciente.

Houve apenas uma complicação pós-operatória. No paciente VGGC, ocorreu necrose de uma pequena porção da ferida cirúrgica com exposição óssea, necessitando de uma limpeza cirúrgica local, com ressecção do osso exposto e fechamento primário da pele. Completou-se o tratamento com antibioticoterapia por 15 dias. 
4 RESULTADOS 
Para análise das medidas, com um nível de probabilidade de erro de 1\%, o teste para comparação de duas variâncias identificou que as variâncias das amostras (pré e pós-operatórias) são homogêneas, podendo ser aplicado o teste t para comparação entre as duas médias (pré e pósoperatórias para cada variável medida).

O índice cefálico modificado no pós-operatório ficou dentro dos valores da normalidade proposto por Diament (2005) entre 0,88 e 1, em todos os pacientes, mostrando-se constante e praticamente sem diferença entre os dois sexos.

A medida pré-operatória do comprimento do crânio (GO) variou de $14.06 \mathrm{~cm}$ a 19,45 cm; da largura do crânio (EE) variou de 9,62 cm a 12,28 cm e do índice craniano (IC) de 60\% a 70\% (Tabela 3).

As medidas GO, EE e o cálculo IC também foram realizadas no pósoperatório, e comparadas com as medidas do pré-operatório. O GO pósoperatório variou de 16,07 cm a 18,96 cm. O EE pós-operatório variou de $11,64 \mathrm{~cm}$ a 13,10 cm. O IC pós-operatório variou de 67\% a 79\%. (Tabela 3).

Os dados do Gráfico 1 mostram a distribuição do IC no préoperatório, os dados do Gráfico 2 mostram a distribuição do IC pósoperatório. 
TABELA 3 - Alterações nas medidas pré e pós-operatórias do comprimento, largura e índice craniano

\begin{tabular}{cccccc}
\hline \multirow{2}{*}{ MEDIDAS } & \multicolumn{2}{c}{ PRÉ-OPERATÓRIO } & \multicolumn{2}{c}{ PÓS-OPERATÓRIO } \\
\cline { 2 - 6 } & $\bar{X}$ & $\mathrm{~S}^{2}$ & $\bar{X}$ & $\mathrm{~S}^{2}$ & $p$ \\
\hline GO (cm) & $16,75(14,06-19,5)$ & 1,75 & $17.20(16,07-18,96)$ & 0,71 & 0,02303 \\
EE (cm) & $10,88(9,62-12,28)$ & 0,53 & $12,55(11,64-13,1)$ & 0,13 & 0,0000001 \\
IC (\%) & $65(60-70)$ & 0,0009 & $73(67-79)$ & 0,001 & 0,0000001 \\
\hline
\end{tabular}

GO: medida da distância entre a glabela e o opistocrânio; EE: medida da distância entre os eurions; IC: índice craniano; $\bar{X}=$ média; $\mathrm{S}^{2}=$ variância. 


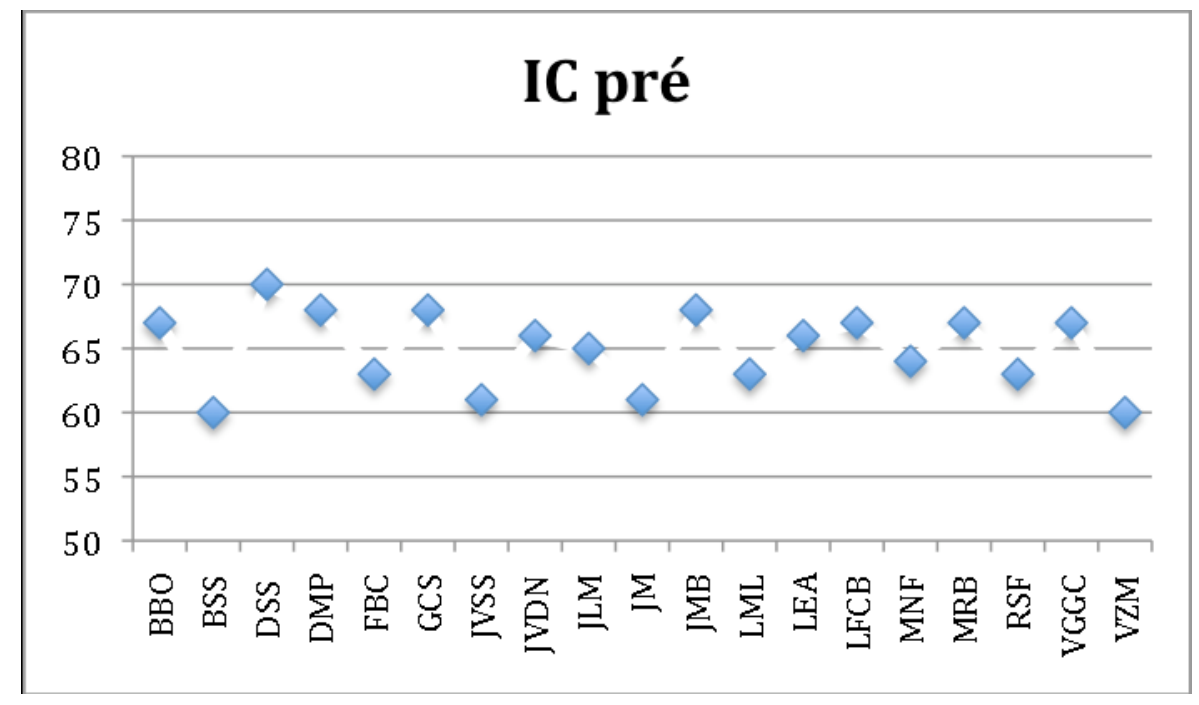

Gráfico 1 - Índice craniano pré-operatório

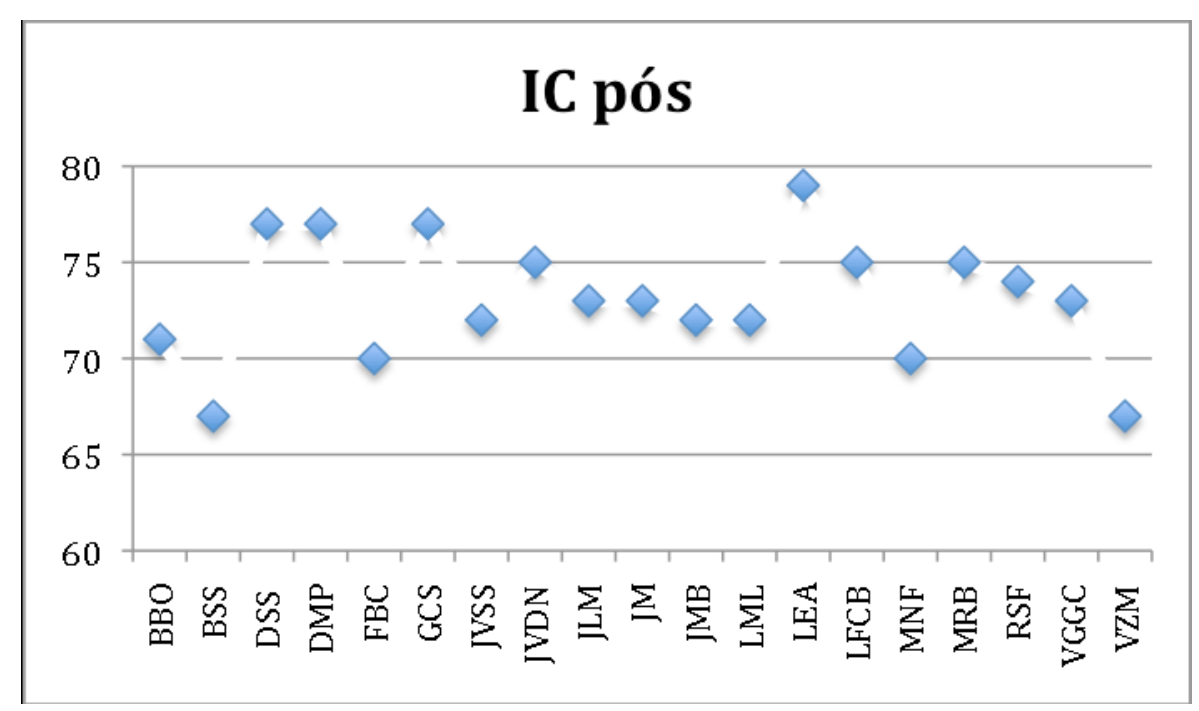

Gráfico 2 - Índice craniano pós-operatório 
O Gráfico 3 compara o IC pré e pós-operatório, observando-se o nítido aumento deste índice em todos os pacientes após a correção cirúrgica. Esta variação foi estatisticamente significativa.

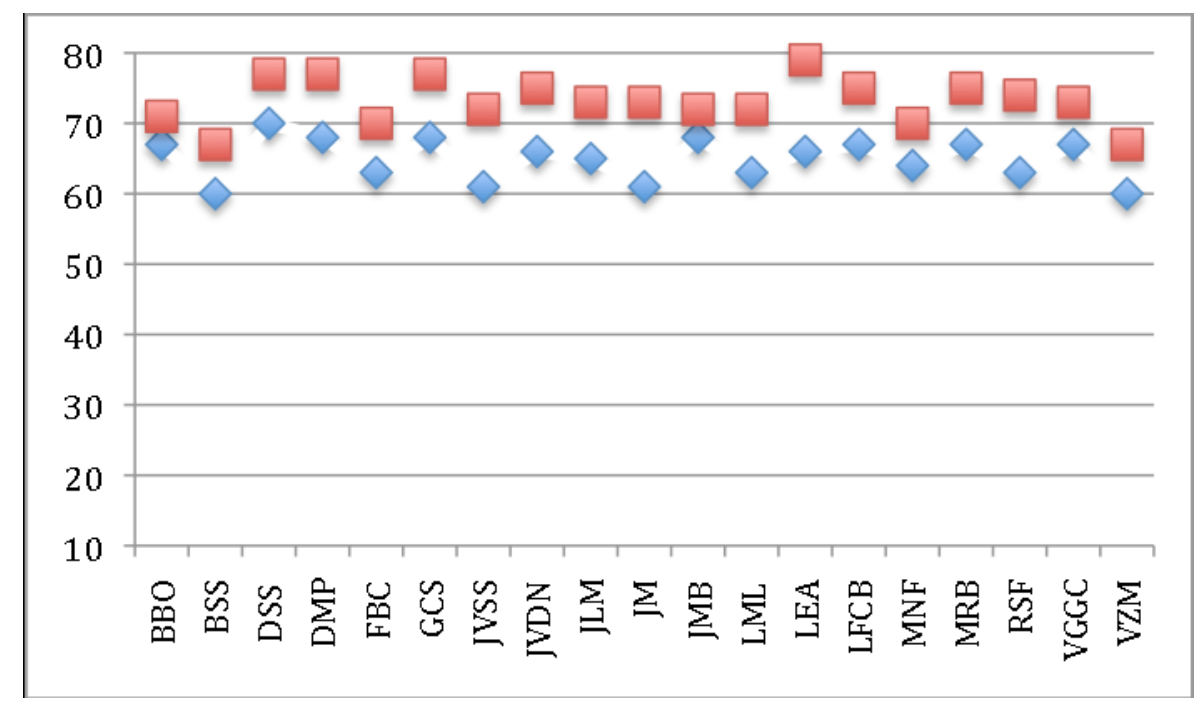

Gráfico 3 - Comparação do índice craniano pós-operatório (vermelho) com o pré-operatório (azul)

As medidas da base do crânio tiveram variação estatisticamente significativa no pós-operatório em relação ao pré-operatório.

A medida CG-TS avaliou a fossa anterior e variou de $2,69 \mathrm{~cm}$ a 3,88 cm no pré-operatório para 3,30cm a 4,12cm no pós-operatório.

No pré-operatório, a medida CG-MAI teve variação de 5,97 cm a 7,51 cm e, no pós-operatório, variou de $6,81 \mathrm{~cm}$ a $7,90 \mathrm{~cm}$.

$\mathrm{Na}$ avaliação do crescimento lateral da fossa média, a medida FO-FO variou de 2,84 cm a 4,29 cm no pré-operatório e, de 3,49 cm a 4,85 cm, no pós-operatório. 
Na fossa posterior, a medida MAI-MAI foi de $3,14 \mathrm{~cm}$ a $4,91 \mathrm{~cm}$ no pré-operatório e, de 3,65cm a 5,11cm, no pós-operatório.

Os dados da Tabela 4 mostram os valores médios e a variância das medidas da base do crânio antes e após a correção cirúrgica.

Tabela 4 - Alterações nas medidas pré e pós-operatórias da base do crânio

\begin{tabular}{cccccc}
\hline \multirow{2}{*}{$\begin{array}{c}\text { MEDIDAS } \\
\text { (CM) }\end{array}$} & \multicolumn{2}{c}{ PRÉ-OPERATÓRIO } & \multicolumn{2}{c}{ PÓS-OPERATÓRIO } & \\
\cline { 2 - 6 } & $\bar{X}$ & $\mathrm{~S}^{2}$ & $\bar{X}$ & $\mathrm{~S}^{2}$ & $p$ \\
\hline CG-TS & $3,28(2,69-3,88)$ & 0,13 & $3,7(3,3-4,12)$ & 0,07 & 0,0004 \\
CG-MAI & $6,72(5,97-7,51)$ & 0,24 & $7,22(6,81-7,9)$ & 0,11 & 0,0009 \\
MAI-MAI & $3,78(3,14-4,91)$ & 0,14 & $4,13(3,65-5,11)$ & 0,12 & 0,0039 \\
FO-FO & $3,99(2,84-4,29)$ & 0,12 & $4,33(3,49-4,85)$ & 0,09 & 0,0041 \\
\hline
\end{tabular}

CG-TS: medida da distância entre a crista galli e o tubérculo selar; CG-MAI: medida da distância entre a crista galli e o meato acústico interno; MAI-MAl: medida da distância entre os meatos acústicos internos; FO-FO: medida da distância entre os forames ovais; $\bar{X}$ =média; $\mathrm{S}^{2}=$ variância 
Ambos os ângulos analisados na base do crânio, Â1 e Â2, tiveram uma diminuição, ou seja, ficaram menos obtusos em $84,2 \%$ das vezes, porém, conforme avaliado nos dados da Tabela 5, não houve diferença estatística na medida desses ângulos no pós-operatório em relação ao préoperatório $(p>0,01)$.

Tabela 5 - Medidas dos ângulos da base do crânio

\begin{tabular}{cccccc}
\hline \multirow{2}{*}{$\begin{array}{c}\text { ÂNGULOS } \\
\text { (graus) }\end{array}$} & \multicolumn{4}{c}{ PRÉ-OPERATÓRIO } & \multicolumn{4}{c}{ PÓS-OPERATÓRIO } \\
\cline { 2 - 6 } & $\bar{X}$ & $\mathrm{~S}^{2}$ & $\bar{X}$ & $\mathrm{~S}^{2}$ & $\mathrm{P}$ \\
\hline$\hat{\mathrm{A} 1}$ & $132,76(123,83-148,45)$ & 43,97 & $130,36(118,79-145,66)$ & 42,81 & 0,2498 \\
$\hat{A} 2$ & $154,07(142,16-173,17)$ & 66,84 & $150,99(138,03-162,35)$ & 51,71 & 0,2197 \\
\hline
\end{tabular}

Â1: medida do ângulo formado pelo násio, centro da sela túrcica e básio; Â2: medida do ângulo formado pelo násio, o centro da sela túrcica e o opístio;

$\bar{X}=$ média ; $\mathrm{S}^{2}=$ variância 
Os dados da Tabela 6 mostram o crescimento proporcional das medidas antropométricas entre o pós e o pré-operatório, avaliado de uma forma geral e nos grupos de idade em que se baseou a escolha da técnica cirúrgica, ou seja, crianças até 1 ano de idade e crianças acima de 1 ano de idade.

Tabela 6 - Crescimento proporcional das medidas antropométricas do crânio

\begin{tabular}{cccc}
\hline Medidas & $<\mathbf{1}$ ano de idade & $>\mathbf{1}$ ano de idade & geral \\
\hline IC & $13,8 \%$ & $11 \%$ & $14 \%$ \\
CG-TS & $16 \%$ & $6 \%$ & $12,5 \%$ \\
CG-MAI & $9,9 \%$ & $2,6 \%$ & $7,2 \%$ \\
MAI-MAI & $11,4 \%$ & $5,4 \%$ & $9,5 \%$ \\
FO-FO & $9,4 \%$ & $6,4 \%$ & $8,5 \%$ \\
\hline
\end{tabular}

IC: índice craniano; CG-TS: medida da distância entre a crista galli e o tubérculo selar; CGMAI: medida da distância entre a crista galli e o meato acústico interno; MAI-MAI: medida da distância entre os meatos acústicos internos; FO-FO: medida da distância entre os forames ovais

Houve melhora estética em todos os casos (Figura 27). Apenas em uma criança, observou-se um remodelamento parcial da região parietal esquerda, permanecendo um abaulamento junto a uma falha óssea, sendo indicada reoperação. Por opção dos pais, a cirurgia não foi realizada e a criança continua em acompanhamento ambulatorial.

A Figura 28 exemplifica as mudanças nas medidas antropométricas em um paciente selecionado aleatoriamente. 


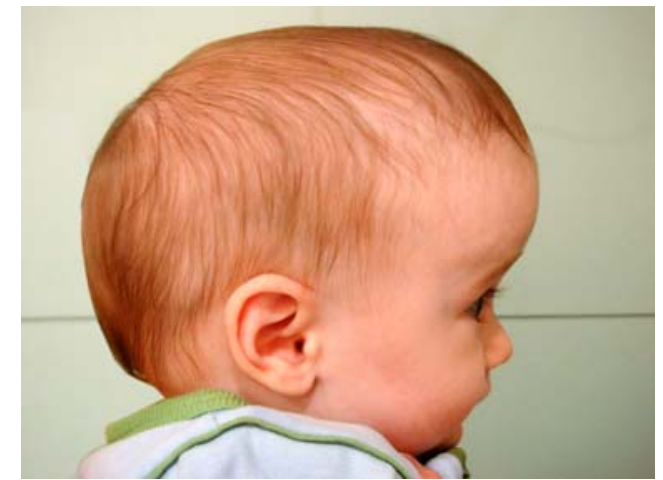

A1

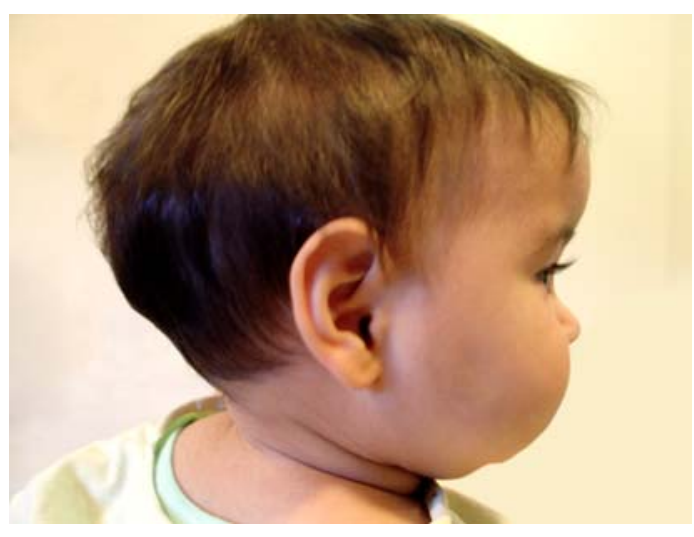

B1

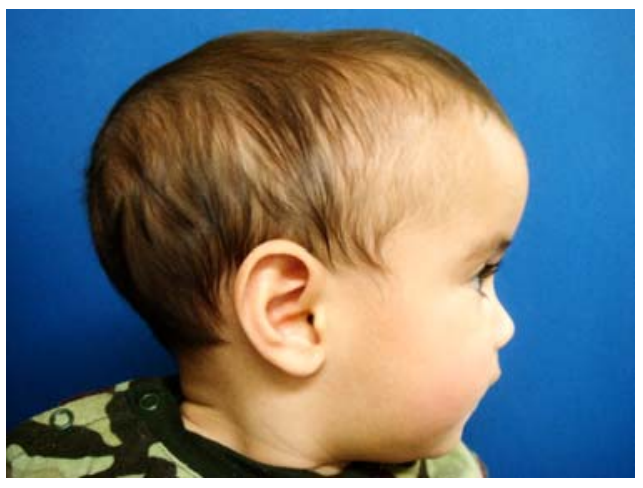

C1

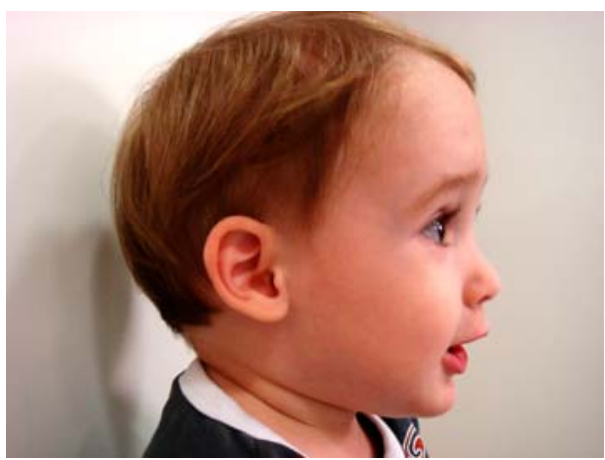

A2

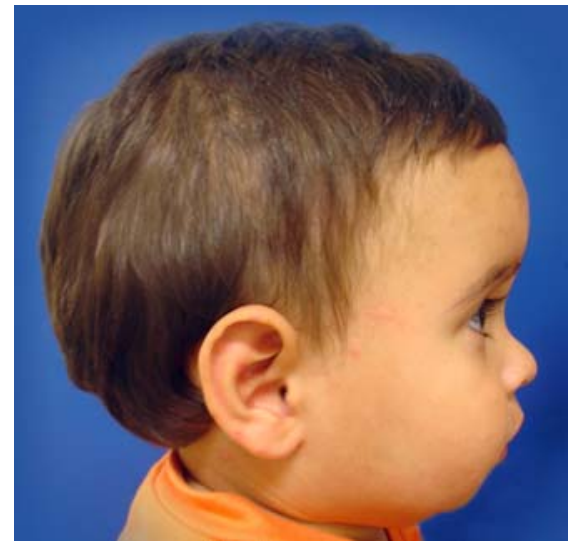

B2

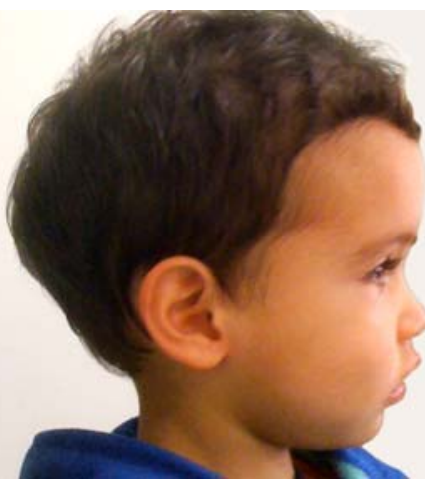

C2

Figura 27 - Fotografias com visão lateral pré (1) e pós-operatórias (2) mostrando o remodelamento craniano. Paciente LEA (A), paciente RSF (B) e paciente MNF (C) 


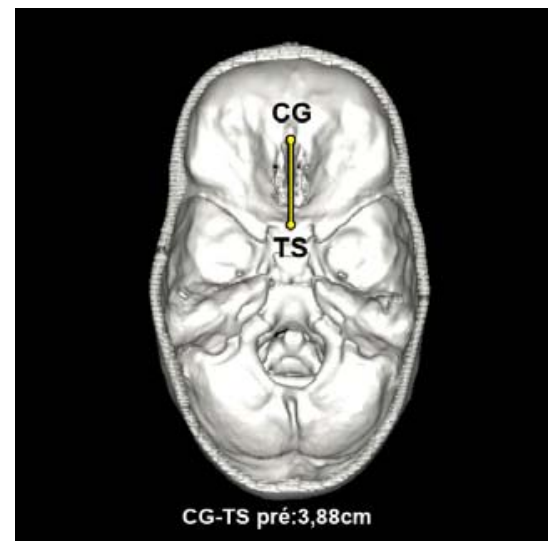

A1

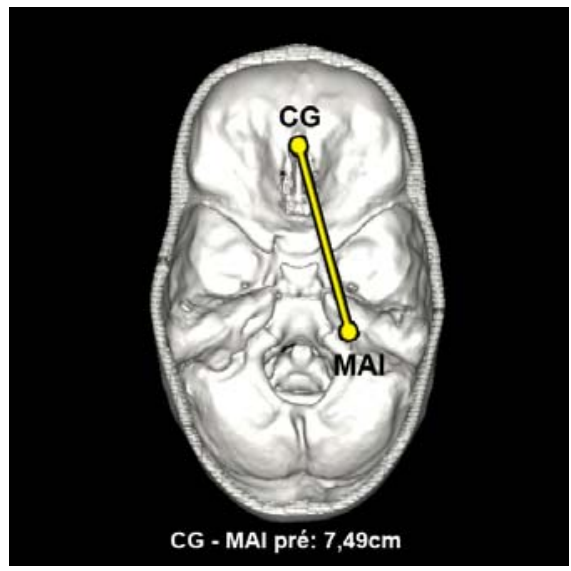

B1

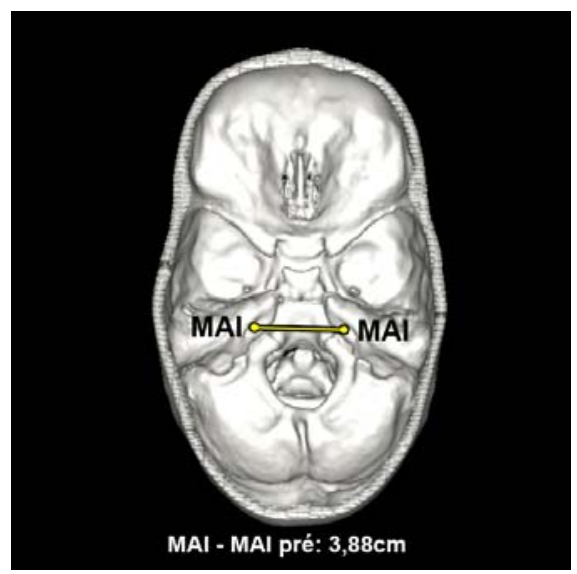

C1

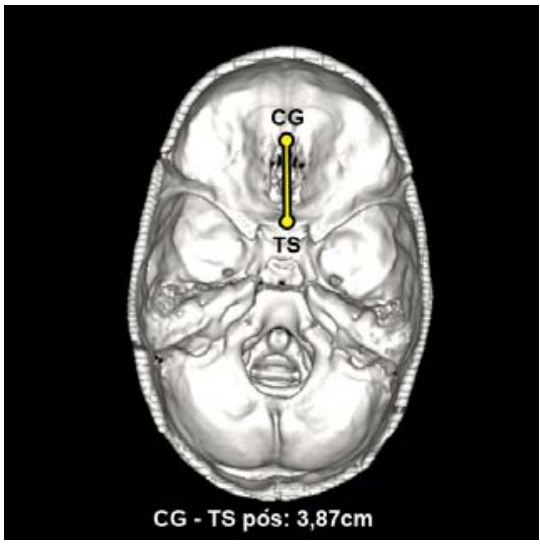

A2

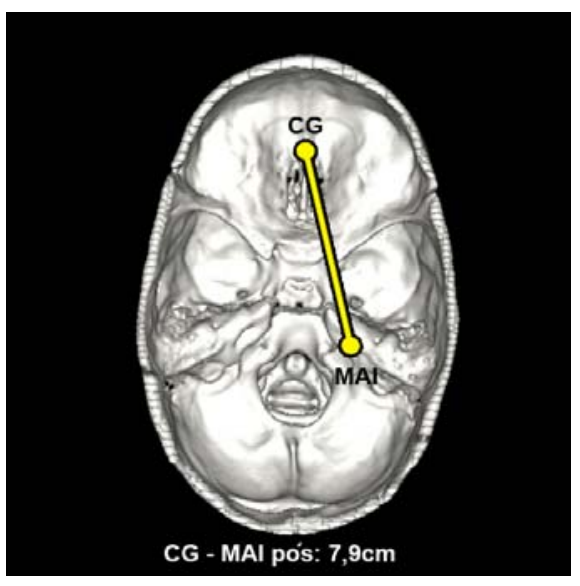

B2

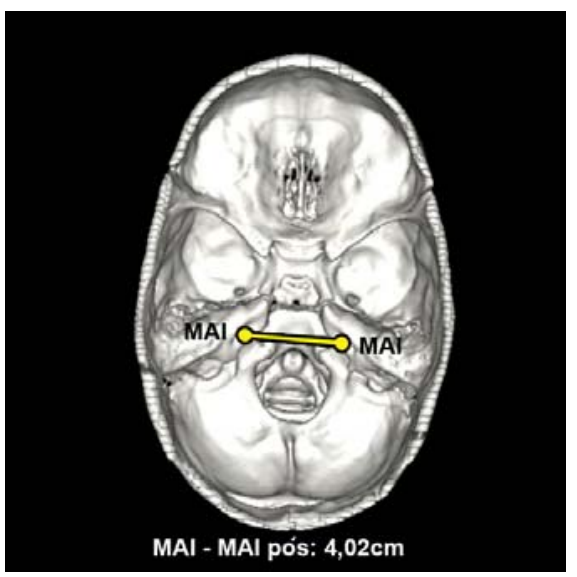

C2

continua 


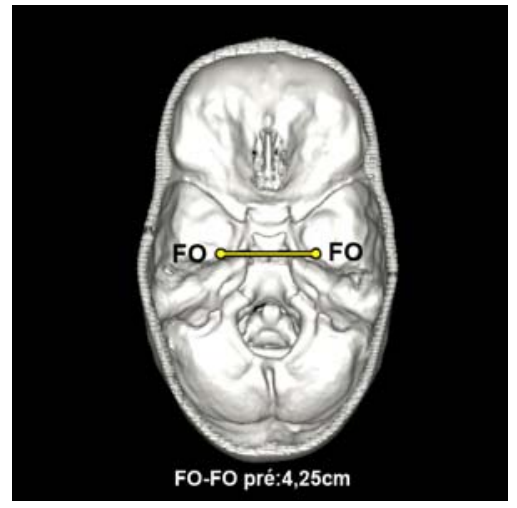

D1

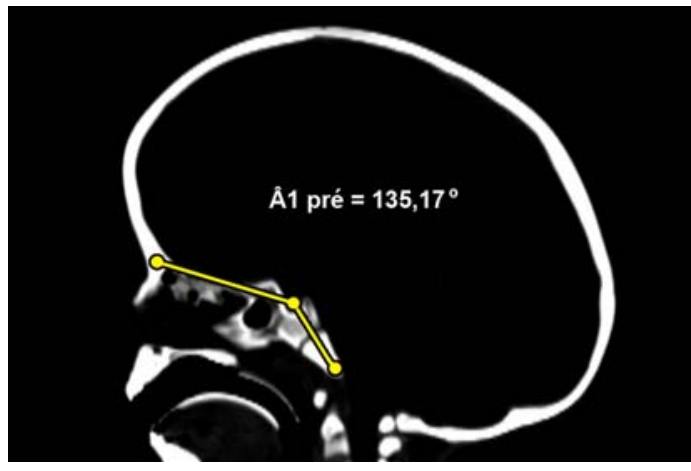

E1

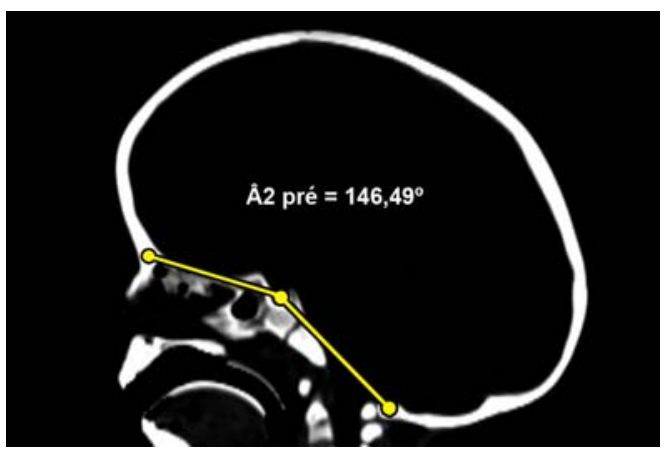

F1

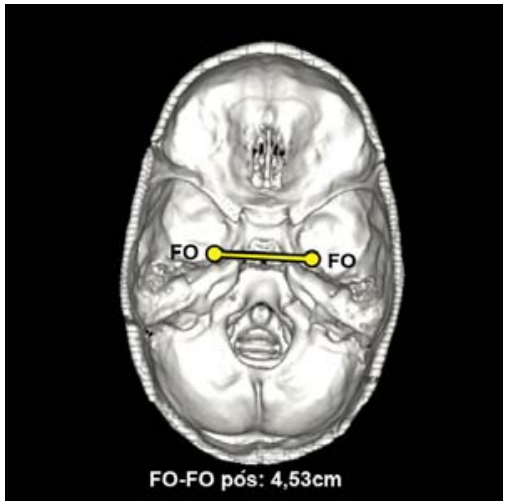

D2

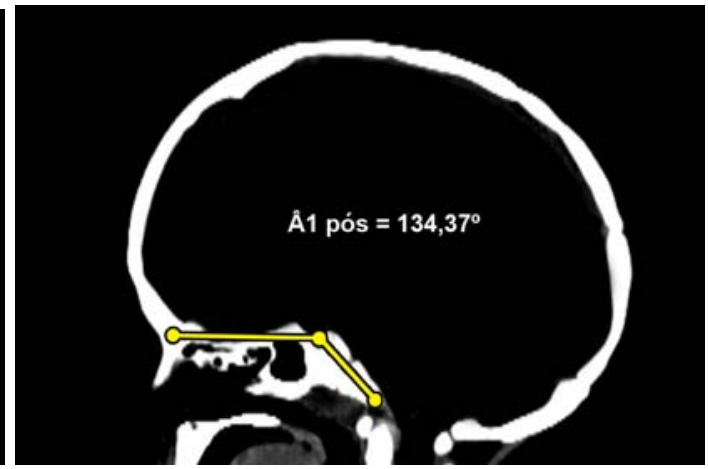

E2

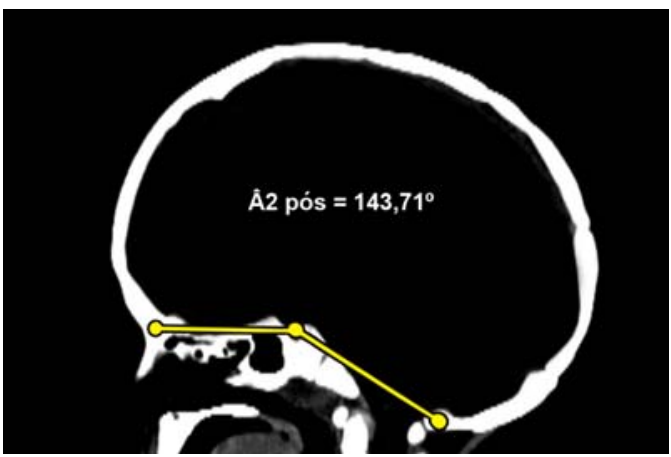

F2

Figura 28 - Medidas antropométricas pré (1) e pós-operatórias (2) da base do crânio. Paciente VZM. A: medida entre a crista galli e o tubérculo selar; $\mathbf{B}$ : medida entre a crista galli e o meato acústico interno; $\mathbf{C}$ : medida entre os meatos acústicos internos; D: medida entre os forames ovais; E: medida do ângulo Â1; F: medida do ângulo Â2. 


\section{DISCUSSÃO}


Os objetivos principais do tratamento cirúrgico das crianças com escafocefalia são aumentar o espaço intracraniano e reorientar os vetores de crescimento do cérebro, melhorando a estética da calota craniana e evitando complicações com o desenvolvimento cerebral e cognitivo dos pacientes.

Conforme descrito por alguns autores, existe a predominância da escafocefalia no sexo masculino (Zeiger et al., 2002; Persing, 2008). Dos 21 pacientes operados, 16 eram do sexo masculino e cinco do sexo feminino.

O exame clínico do crânio associado à TC-3D confirmou o fechamento precoce da sutura sagital em todas as crianças, no qual o crânio era alongado no sentido anteroposterior, estreito no sentido laterolateral, com abaulamento frontal e occipital. Em algumas crianças, palpava-se uma proeminência óssea coincidindo com a topografia da sutura sagital estenosada. Tais características são concordantes com a descrição dos achados diagnósticos da escafocefalia (Cohen Jr., 1986).

Como a relação entre a deformidade craniana na craniostenose nãosindrômica e disfunção psicomotora é menos óbvia, quando comparada às craniostenoses sindrômicas, a indicação da correção cirúrgica tem sobretudo um efeito cosmético (Magge et al., 2002). Existe apenas evidência indireta que o tratamento tardio da escafocefalia está associado com deficiência no desenvolvimento psicomotor (Arnaud et al., 1995). 
Muitos autores indicam a cirurgia nos $2^{\circ}$ ou $3^{\circ}$ mês de vida, com o argumento de minimizar os efeitos constritivos da craniostenose no crescimento cerebral, evitando possíveis efeitos adversos no desenvolvimento psicomotor, e para explorar a maleabilidade óssea nesse período, sobretudo nos que usam a técnica endoscópica (Sgouros, 2005; Massimi et al, 2007; Clayman et al., 2007). Mas, o crescimento rápido do crânio nos primeiros meses de vida e a possibilidade elevada de reossificação, com risco de recorrência da craniostenose e necessidade de nova cirurgia, levam à indicação do tratamento cirúrgico após o $3^{\circ}$ mês de vida, período em que a dura-máter está menos aderida ao crânio e a separação do osso está associada com menor sangramento (Olds et al., 1986; Kane, 2004; Sgouros, 2005; Persing, 2008).

Muitos métodos são descritos para a correção da escafocefalia, mas eles podem ser divididos em três grupos principais: os procedimentos que têm como objetivo liberar as suturas sinostóticas e desfazer a constrição, permitindo uma correção passiva da forma do crânio pelo crescimento cerebral (craniectomias lineares, craniectomias lineares estendidas, craniectomias endoscópicas); procedimentos que combinam forças ativas e passivas, com encurtamento anteroposterior de forma imediata e gradual no intraoperatório seguido do crescimento biparietal passivo (craniectomia em forma de "Pi" e suas modificações) e os procedimentos que fazem a correção ativa da forma do crânio por meio do remodelamento da calota craniana (Greensmith et al., 2008). 
Quando comparado à craniectomia linear, o remodelamento da calota craniana tem resultado cirúrgico melhor na correção imediata e tardia das alterações na escafocefalia nas crianças com mais idade e com deformidades mais graves, visto que o período de maior crescimento cerebral já passou, podendo a realização da craniectomia linear não ser suficiente para o remodelamento natural do crânio, além da possibilidade de permanecerem falhas ósseas maiores (Hudgins et al., 1993; Maugans et al., 1997).

O remodelamento craniano nas crianças com mais de 1 ano de idade não normaliza completamente a forma do crânio. Apesar da redução da bossa frontal e do aumento do diâmetro biparietal, não existe uma diminuição significativa no diâmetro anteroposterior (Smyth et al., 2006).

Nesta série, a idade média das crianças no momento da cirurgia foi de 11,3 meses, e é elevada quando comparada à literatura. O fato é explicado por algumas crianças serem encaminhadas tardiamente para uma avaliação especializada, o tempo de espera para realização do exame diagnóstico e sobretudo pela espera para o agendamento do tratamento cirúrgico. Quando possível foi dada prioridade para internação e tratamento cirúrgico, logo que a criança era matriculada no ambulatório. As duas crianças acompanhadas no consultório particular foram prontamente operadas, após a confirmação diagnóstica.

Apesar da média de idade elevada quando comparada à literatura, os resultados pós-operatórios foram satisfatórios, confirmados pelo resultado estético final e sobretudo pelo aumento e até normalização do índice 
craniano, demonstrando que houve o remodelamento da calota craniana. Observa-se que o índice craniano tende a permanecer estável ou apresentar uma ligeira queda durante o crescimento normal do crânio (ver Tabelas 1 e 2).

O índice craniano tem a vantagem de ser facilmente calculado e obtido pela tomografia computadorizada. Suas desvantagens são não caracterizar outras alterações morfológicas, somente o comprimento e a largura do crânio, e não ter uma origem central definida, portanto, não avaliar a intensidade das bossas frontal e occipital (Marcus et al., 2006; Hankinson et al., 2010).

A variação do índice craniano no pré-operatório demonstra a forma escafocefálica do crânio, com valores de $60 \%$ a 70\%, compatíveis com a literatura, que varia de 60\% a 67\% (David e Simpson, 1982; Kaiser, 1988; Kane, 2004).

Agrawal et al. (2006) descrevem que, após o tratamento cirúrgico, o IC melhorou imediatamente e permaneceu assim até 6 meses após a cirurgia, com uma melhora média de $8,69 \%$ e máxima de $11,1 \%$, como resultado do crescimento rápido e contínuo do cérebro, após a remoção da sutura sagital.

No pós-operatório, houve melhora do índice craniano em todas as crianças, especialmente pelo aumento proporcional maior na medida da largura em relação ao comprimento do crânio. Houve o crescimento do comprimento do crânio em 2,6\% e da largura em 15,3\%. Ao se avaliar pela 
faixa etária, o crescimento proporcional do IC foi maior nas crianças com menos de 1 ano de idade, de 13,8\%, comparado às crianças com mais de 1 ano de idade que foi de $11 \%$. Esta diferença demonstra um remodelamento da calota craniana mais eficaz nas crianças com menos de 1 ano de idade, sobretudo devido ao maior desenvolvimento cerebral que ocorre nesta faixa etária.

Para Moss (1975), a alteração primária na escafocefalia seria uma disostose do osso esfenoide. Perlyn et al. (2001) afirmam, após estudo que avaliou a face endocranial da base do crânio antes e após a correção cirúrgica da craniostenose, que o dismorfismo da base do crânio é secundário ao fechamento precoce da sutura. Essa ideia também é afirmada por Albright e Byrd (1981), que mostram através do estudo microscópico das suturas estenosadas, que as alterações na base do crânio são secundárias à fusão da sutura sagital.

Semelhante ao que ocorre na calota craniana, as maiores alterações na base do crânio estão ao longo do eixo anteroposterior, em especial, na base do crânio posterior (Richtsmeier et al., 1991). Há pequenas alterações no eixo superoinferior e quase não se observam alterações no eixo médiolateral. Após a correção cirúrgica da craniostenose, a ausência de um esperado crescimento médio-lateral da base do crânio sugere que a maior parte do crescimento médio-lateral ocorre no período pré-natal ou nas primeiras semanas após o nascimento, e que não é recuperado com a liberação da sutura fechada. 
Diferente do descrito por Richtsmeier et al. (1991), houve um crescimento médio-lateral entre $8,5 \%$, na medida $\mathrm{FO}-\mathrm{FO}$ até $9,5 \%$ na medida entre os meatos acústicos internos, evidenciando um crescimento lateral da fossa média e da fossa posterior, respectivamente, após a correção cirúrgica da escafocefalia. Este crescimento foi demonstrado pelo aumento estatisticamente significativo nas medidas MAI-MAI e FO-FO.

Lang (1989) descreve as medidas da fossa anterior do crânio normal nas diferentes faixas etárias. A distância entre o forame cecum (início da crista galli) até o tubérculo selar teve nas crianças até 1 ano de idade uma média de 3,77cm e nas crianças entre 2 e 3 anos de idade uma média de 4,04cm. Quando comparados os resultados deste estudo ao trabalho de Lang, observa-se que as médias da medida CG-TS no pré-operatório por faixa etária estavam bem abaixo das médias descritas por Lang, com valores de $3,09 \mathrm{~cm}$ nas crianças abaixo de 1 ano de idade e de 3,66cm nas crianças acima de 1 ano de idade. Após a correção cirúrgica da escafocefalia, houve o crescimento desta medida nas duas faixas etárias, com valores aproximando-se da média normal, respectivamente, de 3,6 cm nas crianças com menos de 1 ano de idade e de $3,88 \mathrm{~cm}$ nas crianças acima de 1 ano de idade. Esta mudança na medida CG-TS demonstra uma normalização da base do crânio anterior, após a correção cirúrgica da escafocefalia.

Nesta série, observou-se um crescimento anterior da base do crânio, avaliado pela medida CG-TS, de 12,5\%, e esse valor foi maior quando a 
medida foi estratificada pela idade, com crescimento proporcional de $16 \%$ nas crianças abaixo de 1 ano de idade.

Observando que as medidas CG-MAI e MAI-MAI fazem os lados de um triângulo na base do crânio, e que teoricamente existe uma simetria entre os lados direito e esquerdo na escafocefalia, houve o crescimento proporcionalmente maior na medida MAI-MAI em relação à medida CG-MAI, respectivamente, de $9,5 \%$ e $7,2 \%$, mostrando o remodelamento da base do crânio, formando-se um triângulo com uma base proporcionalmente mais alargada.

A medida do ângulo da base é eficaz na avaliação das mudanças na base do crânio. Segundo Jeffery e Spoor (2002), este ângulo aproxima os pontos primários de flexão da base, as sincondroses esfenoetmoidal, medioesfenoidal e esfeno-occipital.

O ângulo da base do crânio (Â1) é empregado, desde o uso das radiografias do crânio, na avaliação pré e pós-operatória dos pacientes com craniostenose. Baseado nos dados de flexão e extensão da base do crânio durante o crescimento normal e nas alterações na escafocefalia, outro ângulo foi estudado, o Â2, para se avaliar se as mudanças no remodelamento da calota craniana e na bossa occipital poderiam interferir na posição do opístio, após o tratamento cirúrgico.

Lieberman (2000) mostra que a flexão do ângulo da base de $143^{\circ}$ no $1^{\circ}$ mês pós-natal para $134^{\circ}$ aos 17 anos de idade, e que a maior flexão ocorre dentro do $1^{\circ}$ ano de vida. 
A fusão da sutura sagital na escafocefalia resulta na redução do crescimento médio-lateral da base do crânio e em uma hiperflexão do crânio, como resultado de um movimento posterior e inferior da calota craniana, sobre a sela túrcica, levando à diminuição do ângulo da base (Carmel et al., 1981; Richtsmeier et al., 1991).

David et al. (1982) relatam que o ângulo da base está diminuído em $15^{\circ}$ na escafocefalia, quando comparado ao crânio normal.

DeLeon et al. (2001) em estudo que avaliou pontos de referência na base do crânio, relatam que a morfologia é significativamente diferente nos pacientes, antes e após a correção cirúrgica da escafocefalia e que o ângulo da base, após o tratamento cirúrgico permaneceu constante no $1^{\circ}$ ano pósoperatório. Afirmam também que houve um aumento significativo da distância entre os meatos acústicos internos no pós-operatório, dando suporte à interpretação do deslocamento lateral do osso temporal, após a cirurgia.

Os dados deste estudo são compatíveis com estas afirmações, visto que as medidas dos ângulos Â1 e Â2 não mostraram diferenças estatísticas entre o pré e o pós-operatório. O fato pode ser explicado pelo tempo de acompanhamento de apenas 1 ano ou que, apesar do remodelamento craniano adequado, a cirurgia nesta série de pacientes não modificou a angulação dos ossos da base do crânio.

Independente das hipóteses etiopatogênicas para o fechamento precoce da sutura sagital, os principais fatores para o remodelamento 
craniano adequado são a idade da criança no momento da cirurgia e a escolha da melhor técnica cirúrgica, direcionada para cada paciente, visto que a grau de deformidade craniana é muito variável e não diretamente relacionado à idade da criança. Nas crianças com mais idade, a deformidade craniana já está bem mais definida e pela mineralização óssea existe uma dificuldade maior no remodelamento pós-operatório, que acontece mesmo assim.

Apesar das mudanças antropométricas da base do crânio observadas, após a correção da escafocefalia, interferir ou não no remodelamento da base do crânio não parece ser o procedimento mais importante do tratamento cirúrgico das crianças com escafocefalia, apesar da idade.

As principais finalidades do tratamento cirúrgico da escafocefalia são a correção estética do crânio e a prevenção de alterações neurocognitivas por elevação crônica da pressão intracraniana, além de aliviar a ansiedade dos familiares e facilitar a ligação entre os pais e o filho na primeira infância e, em muitos casos, evitar danos à autoimagem da criança em crescimento. 
6 CONCLUSÕES 
A correção cirúrgica da calota craniana em crianças com escafocefalia, associada ao crescimento do crânio e do cérebro no pósoperatório resultou no remodelamento da convexidade craniana que interferiu no remodelamento da base do crânio, sobretudo às custas de uma expansão transversa (laterolateral), que foi maior que a expansão longitudinal (anteroposterior), confirmando a influência da correção da calota craniana sobre o remodelamento indireto da base do crânio. Apesar deste remodelamento, nesta série de pacientes não se observou diferença estatística nos ângulos da base do crânio estudado, demonstrando que a angulação dos ossos da base está bem definida e não se altera com a cirurgia. 


\section{ANEXOS}


Anexo A: Tabela 7 - Identificação dos pacientes

\begin{tabular}{|c|c|c|c|c|c|}
\hline NOME & SEXO & REGISTRO & $\begin{array}{c}\text { DATA DE } \\
\text { NASCIMENTO }\end{array}$ & $\begin{array}{l}\text { IDADE NA } \\
\text { CIRURGIA }\end{array}$ & $\begin{array}{l}\text { DATA DA } \\
\text { CIRURGIA }\end{array}$ \\
\hline MRB & M & $13743616 \mathrm{I} \mathrm{HC}$ & 26.03 .06 & $12 \mathrm{~m} 14 \mathrm{~d}$ & 09.04 .07 \\
\hline LML & M & 13748466J HC & 29.11 .05 & $16 \mathrm{~m} 27 \mathrm{~d}$ & 25.04 .07 \\
\hline VZM & M & 13776570F HC & 23.03 .06 & $14 \mathrm{~m} 26 \mathrm{~d}$ & 18.06 .07 \\
\hline RSF & M & 6128085G HC & 13.10 .06 & $8 m 21 d$ & 04.07 .07 \\
\hline VMS & M & $13705023 \mathrm{C} \mathrm{HC}$ & 19.10 .04 & $26 \mathrm{~m} 19 \mathrm{~d}$ & 30.07 .07 \\
\hline DMP & M & 1377829F HC & 31.12 .06 & $7 m$ 22d & 22.08 .07 \\
\hline JVDN & M & 13794761D HC & 30.06 .07 & $2 \mathrm{~m} 12 \mathrm{~d}$ & 12.09 .07 \\
\hline VGGC & $\mathrm{F}$ & 441417 HSL & 09.05 .05 & $29 \mathrm{~m} 16 \mathrm{~d}$ & 23.10 .07 \\
\hline $\mathrm{BBO}$ & $\mathrm{F}$ & $6136480 \mathrm{~K} \mathrm{HC}$ & 21.12 .06 & $11 \mathrm{~m} 23 \mathrm{~d}$ & 28.11 .07 \\
\hline LEA & M & 451366 HSL & 11.07 .07 & $5 \mathrm{~m} 27 \mathrm{~d}$ & 07.01 .08 \\
\hline GCS & M & 13788481G HC & 07.03 .07 & $10 \mathrm{~m} 11 \mathrm{~d}$ & 23.01.08 \\
\hline FBC & M & 13799444E HC & 17.11 .06 & $14 \mathrm{~m} 13 \mathrm{~d}$ & 30.01 .08 \\
\hline JM & $F$ & 13816376J HC & 04.10 .07 & $6 m 3 d$ & 07.04 .08 \\
\hline BSS & M & 13820464B HC & 08.08 .06 & $19 \mathrm{~m} 13 \mathrm{~d}$ & 21.05.08 \\
\hline LFCB & M & 13819567K HC & 15.03 .08 & $3 m 19 d$ & 04.06 .08 \\
\hline MNF & M & 13823543A HC & 10.12 .07 & $6 \mathrm{~m} 20 \mathrm{~d}$ & 02.07 .08 \\
\hline JLM & M & $13826396 \mathrm{I} \mathrm{HC}$ & 19.03 .08 & $4 m 4 d$ & 23.07.08 \\
\hline DSS & $\mathrm{F}$ & 13768187C HC & 07.06 .06 & $14 \mathrm{~m} 16 \mathrm{~d}$ & 25.08 .08 \\
\hline YCO & M & 13803003A HC & 30.12 .06 & $8 m 25 d$ & 24.09 .08 \\
\hline JVSS & M & 13845055E HC & 12.05 .08 & $5 \mathrm{~m} 3 d$ & 15.10 .08 \\
\hline JMB & $\mathrm{F}$ & $13850410 \mathrm{C} \mathrm{HC}$ & 26.02 .08 & $8 m 14 d$ & 10.12 .08 \\
\hline
\end{tabular}




\section{Anexo B - APROVAÇAO DO PROTOCOLO DE PESQUISA}

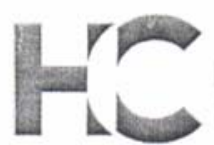

HOSPITHL DAS GLINGEAS

\section{APROVAÇÃO}

A Comissão de Ética para Análise de Projetos de Pesquisa - CAPPesq da Diretoria Clínica do Hospital das Clínicas e da Faculdade de Medicina da Universidade de São Paulo, em sessão de 20.06.07, APROVOU O Protocolo de Pesquisa $\mathbf{n}^{\circ}$ 0275/07, intitulado: "ALTERAÇŌES ANTROPOMÉTRICAS NA BASE DO CRÂNIO EM CRIANÇAS COM CRANIOSSINOSTOSE SAGITAL, SUBMETIDAS Á CORREÇÃO CIRÚRGICA ", apresentado pelo DEPARTAMENTO DE NEUROLOGIA, inclusive o Termo de Consentimento Livre e Esclar ecido.

Cabe ao pesquisudor tiaborar e spresentar à CAPPesq, os relatórios parciais e final sobre a pesquisa (Resclução do Conselho Nacional de Saúde n 196, de 10.10.1996, inciso IX. 2, letra "c")

Pesquisador (a) Responsável: Prof. Dr. José Pindaro Poreira Plese Pesquisador (a) Executante: José Erasmo Dal'Col Lúcio

CAPPesq, 20 de junho de 2007.

PROF. DR. EDUARLO MASSAD

Presidente da Comissão de Ética para Análise de Projetos de Pesquisa

\footnotetext{
Comissāo de Éfica para Anáiso de Projetos de Pesquisa do HCFMUSP e da FMUSR

Rulína do Hospiral das Clinicas da Faculdade de Medicina da Universidade de sto Paula

Sáo Paulo - sp

fone: 011 - 30696442 fax : 011 - $30696492-\theta$-mail : cappesagh cnetusp.bs / secretariacappesa2 ahcnet.usp.b
} 


\title{
Anexo C - TERMO DE CONSENTIMENTO LIVRE E ESCLARECIDO
}

\author{
HOSPITAL DAS CLÍNICAS \\ DA \\ FACULDADE DE MEDICINA DA UNIVERSIDADE DE SÃO PAULO \\ TERMO DE CONSENTIMENTO LIVRE E ESCLARECIDO
}

1. NOME DO PACIENTE .

DOCUMENTO DE IDENTIDADE NN : SEXO : .M F

DATA NASCIMENTO: .......................

ENDEREÇO $\mathrm{N}^{\mathrm{O}}$ APTO:

BAIRRO CIDADE

CEP:. TELEFONE:

2.RESPONSÁVEL LEGAL

NATUREZA (grau de parentesco, tutor, curador etc.) DOCUMENTO DE IDENTIDADE :.... SEXO: $M \quad F$

DATA NASCIMENTO.: ...................

ENDEREÇO: $\mathrm{N}^{\mathrm{O}}$ APTO:

BAIRRO: CIDADE:

CEP: TELEFONE:(

TÍTULO DO PROTOCOLO DE PESQUISA: Alterações antropométricas na base do crânio em crianças com craniossinostose sagital, submetidas à correção cirúrgica.

PESQUISADOR: José Erasmo Dal'Col Lúcio

CARGO/FUNÇÃO: Médico

INSCRIÇÃO CONSELHO REGIONAL No 102971

UNIDADE DO HCFMUSP: Divisão de Neurocirurgia - Grupo de Neurocirurgia Pediátrica .

AVALIAÇÃO DO RISCO DA PESQUISA:

SEM RISCO

RISCO MÍNIMO

RISCO MÉDIO

RISCO BAIXO

RISCO MAIOR

(probabilidade de que o indivíduo sofra algum dano como consequência imediata ou tardia do estudo)

DURAÇÃO DA PESQUISA : 4 anos

Eu, devidamente identificado acima, estou ciente em autorizar a inclusão de meu filho(a) como parte de um protocolo de pesquisa que irá avaliar as alterações nas medidas na base do crânio em crianças com craniossinostose sagital, submetidas à correção cirúrgica. 
A craniostenose sagital, ou escafocefalia, é uma alteração no crescimento do osso da cabeça da criança, causado pelo fechamento antes da hora da moleira. Com este fechamento, a cabeça da criança fica mais apertada dos lados e mais abaulada na testa e na nuca, e precisa de uma cirurgia para se fazer a correção da forma da cabeça.Para a cirurgia, a criança ficará sob anestesia geral, dormindo todo o tempo e sem sentir dor. Será realizado um corte no couro cabeludo que vai de uma orelha até a outra. Após a abertura da pele, será retirada do osso da cabeça a parte alterada, e se realizará um remodelamento de toda a cabeça, seguido do fechamento da pele.

As crianças ficarão internadas na enfermaria da Neurocirurgia Pediátrica, para realização dos cuidados pós-operatórios. Poderá ocorrer inchaço do rosto e da pele da cabeça, febre baixa e necessidade de receber sangue.Os maiores riscos da cirurgia são sangramento durante a abertura e remodelamento da cabeça; possibilidade de se abrir a dura-máter (membrana que protege o cérebro) podendo ter saída de líquor, abertura e cicatrização ruins da ferida, e até mesmo infecção.

Declaro também estar ciente que terei acesso, a qualquer tempo, às informações sobre procedimentos, riscos e benefícios relacionados à pesquisa, inclusive para dirimir eventuais dúvidas; que terei a liberdade de retirar meu consentimento a qualquer momento e de deixar de participar do estudo, sem que isto traga prejuízo à continuidade da assistência; que terei direito à confidencialidade, sigilo e privacidade, assim como disponibilidade de assistência no HCFMUSP, por eventuais danos à saúde, decorrentes da pesquisa. Declaro que, após convenientemente esclarecido pelo pesquisador e ter entendido o que me foi explicado, consinto em participar do presente Protocolo de Pesquisa e autorizo o uso de imagens necessárias do menor que sou responsável.

Na necessidade de outros esclarecimentos durante a pesquisa, Dr José Erasmo Dal Col Lúcio, estará disponível na Divisão de Neurocirurgia - Avenida Dr. Enéas de Carvalho Aguiar, 255 - Instituto Central, $5^{\circ}$ andar, cep: 05403-000 - Cerqueira César - SP. Telefone: (11) 3069 7152, ou no Ambulatório de Neurocirurgia Pediátrica - Prédio dos Ambulatórios $6^{\circ}$ andar, bloco 4.

Declaro que, após convenientemente esclarecido pelo pesquisador e ter entendido o que me foi explicado, consinto em participar do presente Protocolo de Pesquisa

São Paulo, de de 200 
Anexo D: Tabela 8 - Medidas antropométricas

\begin{tabular}{|c|c|c|c|c|c|c|c|c|c|c|}
\hline NOME & $\begin{array}{l}\text { AP } \\
\text { pré }\end{array}$ & $\begin{array}{l}\text { AP } \\
\text { pós }\end{array}$ & $\begin{array}{l}\text { BA } \\
\text { pré }\end{array}$ & $\begin{array}{l}\text { BA } \\
\text { pós }\end{array}$ & $\begin{array}{l}\text { GO } \\
\text { pré }\end{array}$ & $\begin{array}{l}\text { Go } \\
\text { pós }\end{array}$ & $\begin{array}{l}\text { EE } \\
\text { pré }\end{array}$ & $\begin{array}{l}\text { EE } \\
\text { pós }\end{array}$ & $\begin{array}{l}\text { IC } \\
\text { pré }\end{array}$ & $\begin{array}{l}\text { IC } \\
\text { pós }\end{array}$ \\
\hline BBO & 28,0 & 30,50 & 23,0 & 28,0 & 16,55 & 16,79 & 10,88 & 11,93 & 67 & 71 \\
\hline BSS & 32,0 & 32,70 & 27,5 & 31,0 & 18,68 & 18,23 & 11,34 & 12,33 & 60 & 67 \\
\hline DSS & 31,0 & 32,00 & 30,7 & 31,5 & 17,32 & 16,5 & 12,28 & 12,74 & 70 & 77 \\
\hline DMP & 29,0 & 32,00 & 24,0 & 30,3 & 15,77 & 16,46 & 10,78 & 12,79 & 68 & 77 \\
\hline FBC & 32,0 & 32,50 & 25,0 & 28,7 & 17,86 & 18,51 & 11,42 & 12,98 & 63 & 70 \\
\hline GCS & 28,0 & 31,50 & 23,0 & 30,5 & 15,52 & 16,3 & 10,63 & 12,55 & 68 & 77 \\
\hline JVSS & 28,2 & 32,50 & 23,2 & 31,0 & 16,15 & 17,02 & 9,95 & 12,3 & 61 & 72 \\
\hline JVDN & 26,0 & 33,00 & 22,5 & 31,5 & 15,9 & 16,51 & 10,07 & 12,38 & 66 & 75 \\
\hline JLM & 29,3 & 31,20 & 24,4 & 30,0 & 15,52 & 17,14 & 10,53 & 12,61 & 65 & 73 \\
\hline JM & 28,5 & 31,50 & 24,0 & 31,0 & 16,46 & 17,05 & 10,02 & 12,59 & 61 & 73 \\
\hline JMB & 29,0 & 32,00 & 28,0 & 31,0 & 14,06 & $16 ; 07$ & 9,62 & 11,64 & 68 & 72 \\
\hline LML & 32,0 & 35,00 & 26,0 & 34,2 & 18,17 & 18,01 & 11,61 & 13,1 & 63 & 72 \\
\hline LEA & 28,0 & 31,00 & 23,0 & 32,0 & 16,49 & 16,23 & 11,04 & 12,85 & 66 & 79 \\
\hline LFCB & 27,5 & 30,50 & 25,3 & 30,0 & 15,13 & 16,7 & 10,18 & 12,52 & 67 & 75 \\
\hline MNF & 31,2 & 32,00 & 28,5 & 31,2 & 17,26 & 18,32 & 11,21 & 12,83 & 64 & 70 \\
\hline MRB & 31,0 & 32,50 & 25,0 & 29,0 & 17,31 & 16,52 & 11,73 & 12,38 & 67 & 75 \\
\hline RSF & 30,0 & 32,00 & 24,0 & 30,5 & 17,06 & 16,99 & 10,85 & 12,59 & 63 & 74 \\
\hline VGGC & 31,0 & 37,00 & 25,0 & 31,0 & 17,89 & 17,45 & 11,99 & 12,76 & 67 & 73 \\
\hline VZM & 32,0 & 35,00 & 25,0 & 33,5 & 19,45 & 18,96 & 11,73 & 12,85 & 60 & 67 \\
\hline
\end{tabular}


Anexo D: Tabela 8 - Medidas antropométricas (continuação)

\begin{tabular}{clllllllll}
\hline NOME & Â1 pré & Â1 pós & Â2 pré & Â2 pós & $\begin{array}{c}\text { CGMAI } \\
\text { pré }\end{array}$ & $\begin{array}{c}\text { CGMAI } \\
\text { pós }\end{array}$ & $\begin{array}{c}\text { cGTS } \\
\text { pré }\end{array}$ & $\begin{array}{c}\text { cGTS } \\
\text { pós }\end{array}$ \\
\hline BBO & 127,10 & 127,79 & 146,68 & 150,63 & 6,74 & 7,62 & 3,22 & 3,58 \\
\hline BSS & 123,83 & 129,86 & 143,87 & 149,19 & 7,34 & 7,57 & 3,78 & 3,85 \\
\hline DSS & 134,63 & 131,49 & 158,31 & 154,72 & 7,40 & 7,73 & 3,67 & 3,80 \\
\hline DMP & 127,46 & 118,73 & 148,74 & 138,06 & 5,97 & 7,21 & 2,69 & 3,91 \\
\hline FBC & 124,22 & 120,26 & 142,16 & 141,22 & 7,09 & 7,36 & 3,50 & 4,12 \\
\hline GCS & 136,77 & 135,83 & 160,10 & 158,32 & 6,24 & 7,31 & 3,28 & 4,02 \\
\hline JVSS & 129,36 & 128,50 & 150,47 & 148,31 & 6,32 & 6,89 & 2,98 & 3,35 \\
\hline JVDN & 137,59 & 129,38 & 165,15 & 159,71 & 6,41 & 7,38 & 3,06 & 3,85 \\
\hline JLM & 148,45 & 145,66 & 173,17 & 162,35 & 6,11 & 6,85 & 2,69 & 3,41 \\
\hline JM & 132,58 & 129,70 & 150,42 & 146,03 & 6,31 & 6,83 & 3,11 & 3,76 \\
\hline JMB & 145,28 & 137,45 & 165,60 & 158,87 & 6,56 & 6,84 & 2,93 & 3,37 \\
\hline LML & 133,60 & 131,50 & 154,20 & 150,80 & 7,51 & 7,05 & 3,77 & 3,89 \\
\hline LEA & 125,09 & 123,77 & 146,67 & 144,96 & 6,72 & 7,15 & 3,31 & 3,38 \\
\hline LFCB & 128,87 & 125,73 & 157,19 & 151,34 & 6,26 & 6,81 & 3,26 & 3,97 \\
\hline MNF & 136,60 & 124,96 & 151,02 & 147,53 & 6,35 & 7,23 & 2,89 & 3,36 \\
\hline MRB & 129,40 & 128,60 & 152,30 & 143,60 & 6,98 & 6,87 & 3,39 & 3,30 \\
\hline RSF & 130,58 & 139,87 & 154,56 & 160,49 & 6,92 & 7,18 & 3,60 & 3,36 \\
\hline VGGC & 135,94 & 131,53 & 160,28 & 158,20 & 7,06 & 7,39 & 3,38 & 3,75 \\
\hline & 135,17 & 134,37 & 146,49 & 143,71 & 7,49 & 7,90 & 3,88 & 3,87 \\
\hline
\end{tabular}


Anexo D: Tabela 8 - Medidas antropométricas (conclusão)

\begin{tabular}{ccccc}
\hline NOME & MAI-MAI pré & MAI-MAI pós & FO-FO pré & FO-FO pós \\
\hline BBO & 3,72 & 4,17 & 3,94 & 4,10 \\
\hline BSS & 3,82 & 4,07 & 3,78 & 3,92 \\
\hline DSS & 4,91 & 5,11 & 4,34 & 4,85 \\
\hline DMP & 4,11 & 4,46 & 4,17 & 4,58 \\
\hline FBC & 3,58 & 4,05 & 4,25 & 4,45 \\
\hline GCS & 3,69 & 3,85 & 3,88 & 4,17 \\
\hline JVSS & 3,79 & 4,53 & 3,80 & 4,21 \\
\hline JVDN & 3,44 & 3,73 & 3,99 & 4,51 \\
\hline JLM & 3,33 & 3,81 & 3,92 & 4,27 \\
\hline JM & 3,62 & 3,94 & 3,97 & 4,22 \\
\hline JMB & 3,52 & 3,78 & 2,84 & 3,49 \\
\hline LML & 4,11 & 4,15 & 4,25 & 4,33 \\
\hline LEA & 3,68 & 4,13 & 3,80 & 4,27 \\
\hline LFCB & 3,14 & 3,65 & 3,79 & 4,15 \\
\hline MNF & 3,76 & 4,47 & 4,29 & 4,62 \\
\hline MRB & 4,10 & 4,23 & 4,23 & 4,47 \\
\hline RSF & 3,70 & 4,32 & 4,29 & 4,487 \\
\hline VGGC & 3,91 & 4,14 & 4,20 & 4,25 \\
\hline VZM & 3,88 & 4,02 & & \\
\hline
\end{tabular}




\section{REFERÊNCIAS}


Agrawal D, Steinbok P, Cochrane D. Long-term anthropometric outcomes following surgery for isolated sagittal craniosynostosis. J Neurosurg. 2006; 105(5 Suppl Pediatrics): 357-60.

Albright Al, Byrd RP. Surute pathology in craniosynostosis. J Neurosurg. 1981;54:384-7.

Albright AL. Operative normalization of skull shape in sagittal synostosis. Neurosurgery. 1985;17(2):329-31.

Aldridge K, Kane AA, Marsh JL, Yan P, Govier D, Richtsmeier JT. Relationship of brain and skull in pré- and postoperative sagittal synostosis. $J$ Anat. 2005; 206: 373-85.

Anderson PJ, Cox TC, Roscioli T, Elakis G, Smithers L, David DJ, Powell B. Somatic FGFR and Twist mutations are neot a common cause of isolated nonsyndromic single suture craniosynostosis. J Craniofac Surg. 2007; 18(2):312-14.

Antúnez S, Arnaud E, Cruz A, Marchac D, Renier D. Scaphocephaly: part I: índices for scaphocephalic frontal and occipital morphology evaluation: longterm results. J Craniofac Surg. 2009; 20(Suppl 2):1837-42.

Arnaud E, Renier D, marchac D. Prognosis for mental function in scaphocephaly. J Neurosurg. 1995;83:476-9. 
Binaghi S, Gudinchet F, Rilliet B. Three-dimensional spiral CT of craniofacial malformations in children. Pediatr Radiol. 2000;30:856-60.

Burke MJ, Winston KR, Willians S. Normal sutural fusion and the etiology of single sutural craniosynostosis: the microspicule hypothesis. Pediatr Neurosurg. 1995; 22: 241-47.

Carmel PW, Luken MG, Ashcerl GF. Craniosynostosis: Computed tomografic evaluation of skull base and calvaria deformities and associated intracranial changes. Neurosurgery. 1981; 9:366-72.

Clayman MA, Murad GJ, Steele MH, Seagle MB, Pincus DW. History of craniosynostosis surgery and the evolution of minimally invasive endoscopic techniques - The University of Florida experience. Ann Plast Surg. 2007;58(3)285-7.

Cohen Jr MM. Craniosynostosis: Diagnosis, Evaluation, and Management. New York: Raven Press; 1986.

David DJ, Simpson DA. Surgical indications in single suture craniosynostosis. Neurosurgery. 1982;11:466.

David DJ, Poswillo D, Simpson DA. The craniosynostoses: cases, natural history and management. New York: Springer-Verlag; 1982. p7-34.

David L, Glazier S, Pyle J, Thompson J, Argenta L. Classification system for sagittal craniosynostosis. J Craniofac Surg. 2009;20(2):279-82.

Delashaw JB, Persing JA, Jane JA. Cranial deformation in craniosynostosis: a new explanation. Neurosurg Clin North Am. 1991;2:611-20. 
DeLeon VB, Zumpano MP, Richtsmeier JT. The effect of neurocranial surgery on basicranial morphology in isolated sagittal craniosynostosis. Cleft Palate Craniofac J. 2001;38(2):134-46.

Diament A. Exame neurológico do lactente. In: Diament A, Cypel S, Reed UC. Neurologia infantil. $4^{\mathrm{a}}$ ed. São Paulo: Atheneu; 2005. p.57-60.

Enlow DH. Normal craniofacial growth. In: Cohenn Jr MM. Craniosynostosis: diagnosis, evaluation, and management. New York: Raven Press; 1986. p. 131-56.

Farkas LG, Posnick JC, Hreczko TM. Anthropometric growth study of the head. Cleft Palate Craniofac J.1992;29(4):303-10.

Farkas LG, Hreczko TM, Katic MJ, Forrest CR. Proportion indices in the craniofacial regions of 284 healthy north americam white children between 1 and 5 years of age. J Craniofac Surg. 2003;14(1):13-28.

Fearon JA, McLaughlin EB, Kolar JC. Sagittal Craniosynostosis: surgical outcomes and long-term growth. Plast Reconstr Surg. 2006;117(2):532-41.

Fernbach SK, Naidich TP. Radiological evaluation of craniosynostosis. In: Cohenn Jr MM. Craniosynostosis: diagnosis, evaluation, and management. New York: Raven Press; 1986. p.191-214.

Freitas RS, Azzolini TF, Shin JH, Persing JA. Associated (parallel) tomographic findings in patients with single-sutural synostosis. J Craniofac Surg. 2010; 21:411-13. 
Furuya Y, Edwards MSB, Alpers CE, Tress BM, Norman D, Ousterhout DK. Computerized tomography of cranial sutures. Part 2: Abnormalites of sutures and skull deformity in craniosynostosis. J Neurosurg. 1984;61:59-70.

Greensmith AL, Holmes AD, Lo P, Maxiner V, Heggie AA, Meara JG. Complete correction of severe scaphocephaly: the Melbourne method of total vault remodeling. Plast Reconstr Surg. 2008;121(4):1300-10.

Hankinson TC, Fontana EJ, Anderson RCE, Feldstein NA. Surgical treatment of single-suture craniosynostosis: an argument for quantitative methods to evaluate cosmetic outcomes. J Neurosurg Pediatric. 2010;6:193-97.

Heuzé Y, Boyadjiev SA, Marsh JL, Kane AA, Cherkez E, Boggan JE, Richtsmeier JT. New insights into the relationship between suture closure and craniofacial dysmorphology in sagittal nonsyndromic craniosynostosis. $J$ Anat. 2010;217:85-96.

Hoyte DA. The cranial base in normal and abnormal growth. Neurosurg Clin North Am. 1991; 2:515-37.

Hudgins RJ, Burstein FD, Boydston WR. Total calvarial reconstruction for sagittal synostosis in older infants and children. J Neurosurg. 1993;78:199204.

Jane JA, Edgerton MT, Futrell JW, Park TS. Immediate correction of sagittal synostosis. J Neurosurg. 1978;49:705-10.

Jane JA, Persing JA. Neurosurgical treatment of craniosynostosis. In: Cohenn Jr MM. Craniosynostosis: diagnosis, evaluation, and management. New York: Raven Press; 1986. p.249-320. 
Jane Jr JA, Lin KY, Jane JA. Sagittal synostosis. Neurosurg Focus. 2000;9(3):1-6.

Jeffery N, Spoor F. Brain size and the human cranial base: a prenatal perspective. Am J Phys Anthropol. 2002; 118:324-40.

Kaiser G. Sagittal synostosis - it's clinical significance and the results of three different method of craniectomy. Childs Nerv Syst. 1988; 4:223-30.

Kane AA. An overview of craniosynostosis. J Prosthet Orthot. 2004;16(4 Suppl):50-5.

Keating RF. Craniosynostosis: diagnosis and management in the new millennium. Pediatr Ann. 1997; 26:600-12.

Kjaer I. Ossification of the human basicranium. J Craniofac Genet Dev Biol. 1990; 10:29 -38.

Kohn LAP, Vannier MW, Marsh J, Cheverud JM. Effect of premature sagittal suture closure on craniofacial morphology in a prehistoric male hopi. Cleft Palate Craniofac J. 1994; 31(5):387-96.

Kokich VG. The biology of sutures. In: Cohenn Jr MM. Craniosynostosis: diagnosis, evaluation, and management. New York: Raven Press; 1986. p. 81-103.

Lang J. Surgical anatomy of the skull base. Anatomy of the sellar region. In: Samii M, Draf W. Surgery of the skull base. An interdisciplinary approach. Germany: Springer-Verlag; 1989. p27-35. 
Lemire RJ. Embryologic of the skull. In: Cohenn Jr MM. Craniosynostosis: diagnosis, evaluation, and management. New York: Raven Press; 1986. p. 105-109.

Lieberman DE, Ross CF, Ravosa MJ. The primate cranial base: ontogeny, function, and integration. Yearbook of Anthropology. 2000; 43:117-69.

Mackenzie KA, Davis C, Yang A, Macfarlane MR. Evolution of surgery for sagittal synostosis: the role of new Technologies. J Craniofac Surg. 2009; 20(1):129-33.

Magge SN, Westerveld M, Pruzinsky T, Persing JA. Long-term neuropsychological effects of sagittal craniosynostosis on chilg development. J Craniofac Surg. 2002;13(1):99-104.

Marcus JR, Stokes TH, Mukundan S, Forrest CR. Quantitative and qualitative assessment of morphology in sagittal synostosis: mid-sagittal vector analysis. J Craniofac Surg. 2006;17(4):680-6.

Marcus JR, Domeshek LF, Loyd AM, Schoenleber JM, Das RR, Nightingale RW, Mukundan Jr S. use of a three-dimensional, normative database od pediatric craniofacial morphology for modern anthropometric analysis. Plast Reconstr Surg. 2009; 124(6):2076-84.

Massimi L, Tamburrini G, Caldarelli M, Di Rocco C. Effectiveness of a limited invasive scalp approach in the correction of sagittal craniosynostosis. Childs Nerv Syst. 2007;23:1389-1401.

Maugans TA, McComb JG, Levy ML. Surgical management of sagittal synostosis: a comparative analysis of strip craniectomy and calvarial vault remodeling. Pediatr Neurosurg. 1997;27:137-48. 
McMaster RF. Early development of the human basicranium. It's morfogenic controls, growth patterns and relation. In: Bosma JF. Symposium on development of the basicranium. US Departament of Health; Bethesda, Maryland; 1976. p81-93.

Medina LM. Three-dimensional CT maximum intensity projections of the calvária: a new approach for diagnosis of craniosynostosis and fractures. AM J Neuroradiology. 2000;21:1951-4.

Moss ML. The pathogenesis of premature cranial synostosis in man. Acta Anat. 1959; 37:351-70.

Moss ML. Functional anatomy of cranial synostosis. Child's Brain. 1975; 1:23-33.

Noden DM. Cell movements and control of patterned tissue assembly during craniofacial development. J Craniofac Genet Dev Biol. 1991; 11:192-213.

Noden DM. Vertebrate craniofacial development: novel approaches and new dilemmas. Curr Opin Genet Dev. 1992; 2:576-81.

Olds MV, Storrs B, Walker ML. Surgical treatment of sagittal synostosis. Neurosurgery. 1986;18(3):345-47.

Opperman LA. Cranial Sutures as intramembranous bone growth sites. Dev Dyn. 2000; 219:472-85.

Ozaki W, Buchan S, Muraszko K, Coleman D. Investigation of the influences of biomechanical force on the ultrastructure of human sagittal craniosynostosis. Plast Reconstr Surg. 1998; 102 (5):1385-94. 
Park TS, Robinson S. Nonsyndromic craniosynostosis. In: American Society of Pediatric Neurosurgeons, section of Pediatric Neurosurgery of the A.A.N.S. Pediatric Neurosurgery: surgery of the developing nervous system. $4^{\text {th }}$ ed. Philadelphia: W.B. Saunders Company; 2001.p345-61.

Perlyn CA, Marsh JL, Pilgram TK, Kane A. Plasticity of the endocranial base in nonsyndromic craniosynostosis. Plast Reconstr Surg. 2001; 108: 294-301.

Persing JA. Introduction to craniosynostosis. Neurosurg Focus. 2000;9(3): 1.

Persing JA. Management considerations in the treatment of craniosynostosis. Plast Reconstr Surg. 2008; 121(4):1-11.

Persson KM, Roy W A, Persing JA, Rodeheaver GT, Winn HR. Craniofacial growth following experimental craniosynostosis and craniectomy in rabbits. $J$ Neurosurg. 1979; 50:187-97.

Plese JPP. Contribuição para o tratamento cirúrgico da craniostenose simples da sutura sagital [tese livre-docência]. São Paulo: Faculdade de Medicina, Universidade de São Paulo; 1980.

Richtsmeier JT, Grausz HM, Morris GR, Marsh JL, Vannier MW. Growth of the cranial base in craniosynostosis. Cleft Palate Craniofac J. 1991; 28 (1):55-67.

Richtsmeier JT, Cole TM, Krovitz G, Valeri CJ, Lele S. Pre-operative morphology and development in sagittal synostosis. J Craniofac Genet Dev Biol. 1998,18:64-78. 
Ruiz-Correa S, Sze RW, Starr, JR et al. New Scaphocephaly Severity Indices of Sagittal Craniosynostosis: A Comparative Study With Cranial Index Quantifications. Cleft Palate Craniofac J. 2006; 43(2):211-21.

Schmelzer RE, Perlyn CA, Kane AA, Pilgram TK, Govier D, Marsh JL. Identifying reproducible patterns of calvarial dysmorphology in nonsyndromic sagittal craniosynostosis may affect operative intervention and outcomes assessment. Plast Reconstr Surg. 2007;119(5):1546-52.

Sgouros S. Skull vault growth in craniosynostosis. Childs Nerv Syst. 2005;21:861-70.

Silverman FN. Some features of developmental changes observed clinically in the sphenoid and basicranium. In: Bosma JF. Symposium on development of the basicranium. Bethesda, Maryland: US Departament of Health; 1976. p.319-44.

Slomic AM, Bernier JP, Morissette J, Reinier D. A craniometric study of sagittal craniosynostosis. J Craniofac Genet Dev Biol. 1992;12(1):49-54.

Smyth MD, Tenenbaum MJ, Kaufman CB, Kane AA. The "clamshell" craniotomy technique in treating sagittal craniosynostosis in older children. $J$ Neurosurg. 2006;105(4 Suppl Pediatrics):245-51.

Smoker WRK. Craniovertebral junction: normal anatomy, craniometry, and congenital anomalies. Radiographics. 1994;14(2):255-77.

Sperber GH. Craniofacial embryology. $4^{\text {th }}$ ed. London: Wright. May R, Sheffer DB. 1989. 
Stein SC, Schut L. Management of scaphocephaly. Surg Neurol. 1997;7(3):153-55.

Sven Kreiborg DDS. Posnatal growth and development of the craniofacial complex in premature craniosynostosis. In: Cohen Jr MM. Craniosynostosis: diagnosis, evaluation, and management. New York: Raven Press; 1986. p. 157-189.

Wackenheim A, Christmann D. Malformations du crane, du cerveau et de la region cervico-occipitale. Encycl Med Chir Radiodiagnostic II. 1977; $3164 \mathrm{~A}^{10}: 4.6 .06$.

Waitzman AA, Posnick JC, Armstrong DC, Pron GE. Craniofacial skeletal measurements based on computed tomography: part I. Accuracy and reproducibility. Cleft Palate Craniofac J. 1992a; 29(2): 112-17.

Waitzman AA, Posnick JC, Armstrong DC, Pron GE. Craniofacial skeletal measurements based on computed tomography: part II. Normal values and growth trends. Cleft Palate Craniofac J. 1992b; 29(2): 118-28.

Willians PL, Bannister LH, Berry MM, Collins P, Dyson M, Dussek JE, Ferguson MWJ. Gray's anatomy. $38^{\text {th }}$ ed. Edinburgh: Churchill Livingstone; 1995.

Willians JK, Ellenbogen HG, Gruss JS. State of the art in craniofacial surgery: nonsyndromic craniosynostosis. Cleft Palate Craniofac J. 1999;36(6):471-85.

Yu JC, Mcclintock JS, Gannon F, Gao XX, Mobasser JP, Sharawy M. egional differences of dura osteoinductios: squamous dura induces osteogenis, 
sutural dura induces cohondrogenesis and osteogenesis. Plast Reconstr Surg. 1997; 100:23-31.

Zeiger JS, Beaty TH, Hetmanski JB, Wang H, Scott AF, Kasch L, Raymond G, Jabs EW, VanderKolk C. Genetic and environmental risk factors for sagittal craniosynostosis. J Craniofac Surg. 2002;13(5):602-06. 